\title{
Synthesis, crystal structure, vibrational, optical properties, thermal analysis and theoretical study of a new Sn(IV) complex $\left(\mathrm{C}_{5} \mathrm{H}_{14} \mathrm{~N}_{2}\right)_{2}\left[\mathrm{SnCl}_{6}\right]_{2} .5 \mathrm{H}_{2} \mathrm{O}$
}

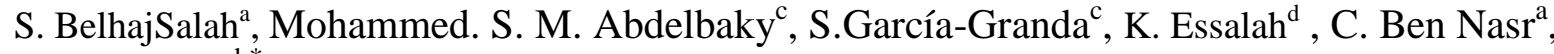 \\ M. L. Mrad ${ }^{\mathrm{a}, \mathrm{b}^{*}}$
}

${ }^{a}$ Université de Carthage, Laboratoire de Chimie des Matériaux, Faculté des Sciences de Bizerte, 7021 Jarzouna, Tunisie.

${ }^{b}$ Université Tunis El Manar, Institut préparatoire aux études d'ingénieurs El manartunis, Tunisie

${ }^{c}$ Department of Physical and AnalyticalChemistry, University of Oviedo-CINN, 33006 Oviedo, Spain.

${ }^{d}$ Université de Tunis El Manar, Unité de Recherche en Sciences Fondamentales et Didactiques. Equipe de Chimie Théorique et Réactivité (URI4ES10), Institut préparatoire aux études d'ingénieurs d'El Manar. B.P.244 El Manar II, 2092 Tunisie.

*Corresponding author: E-mail address: mraded@yahoo.fr

\begin{abstract}
In this study, a new organic-inorganic hybrid metal compound $\left(\mathrm{C}_{5} \mathrm{H}_{14} \mathrm{~N}_{2}\right)_{2}\left[\mathrm{SnCl}_{6}\right]_{2} .5 \mathrm{H}_{2} \mathrm{O}$ was crystallized at room temperature in the orthorhombic system (space group $P 22_{1} 2_{1} 2_{1}$ ) where the structure is determined by single crystal X-ray diffraction analysis. The examination of the structure shows the cohesion and stability of the atomic arrangement result from the establishment of $\mathrm{N}-\mathrm{H} \cdots \mathrm{Cl}, \mathrm{O}(\mathrm{W})-\mathrm{H}(\mathrm{W}) \cdots \mathrm{Cl}, \mathrm{N}-\mathrm{H} \cdots \mathrm{O}(\mathrm{W})$ and $\mathrm{O}(\mathrm{W})-\mathrm{H}(\mathrm{W}) \cdots \mathrm{O}(\mathrm{W})$ hydrogen bonds between 1-methylpiperazine-1,4-diium $\left(\mathrm{C}_{5} \mathrm{H}_{14} \mathrm{~N}_{2}\right)^{2+}$ cations, isolated $\left(\mathrm{SnCl}_{6}\right)^{2-}$ anions and water molecules to form organic and inorganic layers parallel to the (a, c) plane and alternate along the b-axis. Hirshfeld surface analysis was used to investigate intermolecular interactions, as well 2D fingerprint plots were conducted to reveal the contribution of these interactions in the crystal structure quantitatively. The solid phase FTIR and FT-Raman spectra of this compound have been recorded in the regions $400-4000$ and $100-500 \mathrm{~cm}^{-1}$, respectively. The vibrational frequencies were also predicted from the calculated intensities by DFT method and were compared with the experimental frequencies, which yield good agreement between observed and calculated frequencies. Besides, the optical proprieties were investigated by UV-visible and photoluminescence spectroscopy studies in the region 200-700 $\mathrm{nm}$ and the electronic properties HOMO and LUMO energies were measured by TD-DFT approach. Moreover, this
\end{abstract}


compound was characterized by thermal analysis between 300 and $500 \mathrm{~K}$ which revealing two phase transitions. Finally, X-ray photoelectron spectroscopy (XPS) analysis is reported to determine the degree of oxidation of tin in this compound and analyzing the surface chemistry of $\left(\mathrm{C}_{5} \mathrm{H}_{14} \mathrm{~N}_{2}\right)_{2}\left[\mathrm{SnCl}_{6}\right]_{2} .5 \mathrm{H}_{2} \mathrm{O}$.

Keywords: Organic-inorganic hybrid; X-ray diffraction; spectroscopy; Hirshfeld surface, XPS; Thermal decomposition.

\section{Introduction}

In recent years, the attention in organic-inorganic compounds has increased. In general, the combination of two extremely different components provides a way to design new hybrid materials as well as additional properties can be introduced, which the individual inorganic or organic components do not have, such as electronic [1,2], optical [3,4] magnetic $[5,6]$ and ferroelectric properties [7,8] etc... This valuable features of hybrids, open promising new pathways for the use in a very broad application areas like catalysis, non-linear optical response (NLO), development of new pharmaceutical drugs etc...[9-11]. Recently hybrid compounds based on piperazines are generally considered is a broad class of chemical compounds with many important pharmacological properties. Moreover, piperazine and substituted piperazine nuclei had constituted an attractive pharmacological scaffold present in various potent marketed drugs. In fact, hybrid materials are traditionally used in medicine, with the presence of piperazine introduces a very important synthetic strategy discovery in drug due to its easy modifiability, proper alkalinity and water solubility. In fact, experimental studies on numerous halogenometalates with elements of groups 14 and 15 based on various piperazine cations have exhibit interesting and useful properties [12-16]. In that context, this paper is a continuation of our interest on the characterization of hybrid materials hexachlorostannate based. We have succeeded in synthesizing a new acentric compound of hexachlorostannate based on 1-methylpiperazine-1,4-diium cation and have concentrated to the studies of single-crystal X-ray diffraction, thermal and vibrational properties as well as DFT calculations of new organic-inorganic compound $\left(\mathrm{C}_{5} \mathrm{H}_{14} \mathrm{~N}_{2}\right)_{2}\left[\mathrm{SnCl}_{6}\right]_{2} .5 \mathrm{H}_{2} \mathrm{O}$.

\section{Results and discussion}

\subsection{Description of the structure}

In the present study, we reported a new hybrid compound, $\left(\mathrm{C}_{5} \mathrm{H}_{14} \mathrm{~N}_{2}\right)_{2}\left[\mathrm{SnCl}_{6}\right]_{2} .5 \mathrm{H}_{2} \mathrm{O}$, based on tin and piperazine molecule, and we examined the hydrogen bonding in the crystal 
structure. The title organic hexachlorostannate material crystallizes in acentric setting in the chiral orthorhombic space group $P 2{ }_{1}{ }_{1}{ }_{2}{ }_{1}$. Refining the structure in this acentric space group gives a value of $0.013(16)$ for the Flack parameter. This value shows that the atomic arrangement corresponds to the correct absolute structure. The crystallographic analysis reveals that the crystal structure consists of two hexachlorostannate di-anions, forming a quasi-regular octahedral arrangement, five water molecules in general position and two cristallographicaly independents 1-methylpiperzine-1,4-diium dications, such as two imino groups of the two piperazine ring are protoned at N1, N2, N3 and N4. The molecular geometry and the atom-numbering scheme of this compound are shown in Fig. 1. The organic molecule exhibited a regular spatial configuration with normal $\mathrm{C}-\mathrm{C}$ and $\mathrm{C}-\mathrm{N}$ distances and $\mathrm{C}-\mathrm{C}-\mathrm{N}$ and $\mathrm{C}-\mathrm{N}-\mathrm{C}$ angles. Indeed, the $\mathrm{C}-\mathrm{C}$ bond lengths vary from 1.493(9) to 1.524(9) $\AA$. The mean value of the $\mathrm{C}-\mathrm{N}$ length is $1.5259 \AA$ and the $\mathrm{C}-\mathrm{C}-\mathrm{C}, \mathrm{C}-\mathrm{C}-\mathrm{N}$ and $\mathrm{C}-\mathrm{N}-\mathrm{C}$ angles range between 104.5(6) and $119.9(6)^{\circ}$ (Table.2). These values are comparable to the corresponding ones previously reported for similar piperazine complexes [31, 32].

In $\left[\mathrm{SnCl}_{6}\right]^{2-}$ anion, the central tin(IV) ion is coordinated by six chlorine atoms to form a slightly distorted octahedral coordination geometry. Selected bond distances and angles are listed in Table 2. The $\mathrm{Sn}-\mathrm{Cl}$ distances range from 2.670(3) to 2.733(3) $\AA$. The bond angles show a slight deviation from the ideal value of $90^{\circ}$ and $180^{\circ}$. The equatorial angle vary from 84.87(10)-96.76(10) ${ }^{\circ}$, while the axial angle are in the range of 175.9(1)-179.2(2) ${ }^{\circ}$. These values are in good agreement with those found for other hexachlorostannates (IV) [33,34]. This slight distortion is correlated to deformations resulting from hydrogen bonding interactions (Table 3).

The hydrogen bonding interactions do not only affect the geometry of the two $\left[\mathrm{SnCl}_{6}\right]^{2-}$ octahedra, they are also the main force guiding the overall molecular arrangement of the ions in the crystal lattice. So the examination of the structure has shown that the main feature of the atomic arrangement in this compound is the existence of infinite layers composed of anionic and cationic groups parallel to $(a, c)$ plane at $\mathrm{y}=\mathrm{n} / 2$, spared by distance $\mathrm{d}$ $=5.8735 \mathrm{~A}^{\circ}$ equal to $\mathrm{b} / 2$ and linked together by $\mathrm{O}-\mathrm{H} \ldots \mathrm{O}$ and $\mathrm{O}-\mathrm{H} \ldots \mathrm{Cl}$ hydrogen bonds (Fig. 2).

Fig S. 1 shows that in each layer, the anionic entities $\left[\mathrm{SnCl}_{6}\right]^{2-}$ are interconnected via $\mathrm{O}-\mathrm{H}$... Cl hydrogen bonds generated by the water molecules to build infinity chains developed along the c-axis direction (Fig. S.1). Moreover, the 1-methylpiperzine-1,4-diium 
di-cations are inserted between these chains via the above mentioned additional $\mathrm{N}-\mathrm{H}$... hydrogen bonds that give rise to this layer ( Table 3). The hydrogen bonding interactions and the Van der Waals interactions between these layers give rise to a three-dimensional network and add stability to the structure.

In addition the projection along the $c$-axis of the structure of the title compound shows that, the 3D-inorganic structure provides 1D channels that propagate along the crystallographic c-axis (Fig. 3a). These channels with pore diameter size of $\sim 16 \mathrm{~A}^{\circ}$, constitute a potential cation-accessible area of the crystal (Fig. 3b). These organic 1-methylpiperazine1,4-diium $\left(\mathrm{C}_{5} \mathrm{H}_{14} \mathrm{~N}_{2}\right)^{2+}$ fit into these channels and interact with means the inorganic framework both electrostatic interactions and via hydrogen bonds.

\section{Hirshfeld Surface}

The analysis of intermolecular interactions using tools based on the Hirshfeld surface represent a method allowing chemists to know the behavior of intermolecular interactions in the crystal. The Hirshfeld surface of the title compound was generated using Crystal Explorer 3.1 [21]. In this compound, Intermolecular contacts were analyzed around the asymmetric unit. Fig. 4 shows the different intermolecular interactions around the organic and inorganic groups computed by Hirshfeld surfaces $\mathrm{d}_{\text {norm }}$ mapping. Fig. 4 a represent the major contributor contacts on the Hirshfeld surface. It shows that the hydrogen bonds $\mathrm{Ow}-\mathrm{H} \ldots \mathrm{Cl}, \mathrm{Ow}-\mathrm{H} \ldots \mathrm{Ow}$, and $\mathrm{N}-\mathrm{H} . . . \mathrm{Ow}$ are represented by red spots, whereas the $\mathrm{H} . . \mathrm{H}$ and $\mathrm{Cl}$... Cl contacts are located in the blue and white areas respectively. It is obvious that the red regions rich in hydrogen bonds on the $\mathrm{d}_{\text {norm }}$ surface are in good agreement with the results observed by X-ray diffraction.

The 2D fingerprint plots can be deconstructed to highlight particular atom pair contacts for separate the contributions from different interaction types that overlap in the full fingerprint (Fig. 4b) [35-39]. On the other hand, this analysis can be done by quantitative calculation of 2D fingerprint plots through the Crystal Explorer program [21]. The fingerprint plot of the intermolecular contacts for the title compound is shown in Fig. 5.

Overall, $\mathrm{H} . . \mathrm{Cl}$ contacts are the most favorable $(63.3 \%)$ in crystal packaging. As previously indicated in Table. 3, there are ten hydrogen bonds in our crystal structure of the same type $\mathrm{Ow}-\mathrm{H}$...Cl. However, only the $\mathrm{HW} . . . \mathrm{Cl}$ contacts appear in this compound whereas those of $\mathrm{H}(\mathrm{C}) \ldots \mathrm{Cl}$ and $\mathrm{H}(\mathrm{N}) \ldots \mathrm{Cl}$ contacts are absent, because the atom $\mathrm{Hw}$ is much more 
electropositive than $\mathrm{H}(\mathrm{C})$ ) and $\mathrm{H}(\mathrm{N})$ atoms, so is strongly attracted by the electronegative chlorine atoms. Two sharp symmetric spikes in the two-dimensional fingerprint maps, with a maximum de+ $\mathrm{di} \sim 2.35 \AA$, represent these contacts. This value is less than the sum of Van der Waals radii of chlorine $(1.75 \AA)$ and hydrogen $(1.20 \AA)$ atoms confirming that the intercontact is considered as being close contact. The H...H contacts represented of narrow and symmetrical points with $\left(\mathrm{d}_{\mathrm{e}}+\mathrm{d}_{\mathrm{i}} \sim 2.0 \AA\right)$. Furthermore they cover $23.2 \%$ of the total surface of Hirshfeld and represented the second most frequent interactions due to the abundance of hydrogen atoms on the molecular surface. Similarly, the O...H / H... intermolecular interactions appear as two very long spikes in the 2D fingerprint plots where $\mathrm{d}_{\mathrm{e}}+\mathrm{d}_{\mathrm{i}} \sim 1.8 \AA$ .They constitute the third most occurrent contacts $(8.4 \%)$, in agreement with the presence of eight hydrogen bonds of types $\mathrm{D}-\mathrm{H} \ldots \mathrm{Ow}$ in this structure. The $\mathrm{Cl} \ldots \mathrm{Cl}$ contacts $(3.8 \%)$ appear in the middle of the 2D fingerprint maps with an acute single peak at $d_{e}+d_{i} \sim 3.8 \AA$, this value is due from a long interatomic contact. The percentages of contributions for different contacts in the crystal structure of the title material are gathered in Fig S.2. This quantitative analysis shows that the intermolecular contacts $\mathrm{H} \ldots \mathrm{Cl}$ are most abundant contacts, they constitute the driving force in this crystal packing.

Finally, the Hirshfeld surfaces certainly allow a detailed quantitative and qualitative scrutiny by displaying all the intermolecular interactions and specify its placement within the crystal and this methodology has very important promise in crystal engineering.

\subsection{Infrared Spectroscopy}

To gain more informations on the crystal structure, we have undertaken a vibrational study using infrared absorption. The infrared spectrum of $\left(\mathrm{C}_{5} \mathrm{H}_{14} \mathrm{~N}_{2}\right)_{2}\left[\mathrm{SnCl}_{6}\right]_{2} .5 \mathrm{H}_{2} \mathrm{O}$ measured between 400 and $4000 \mathrm{~cm}^{-1}$ is shown in Fig. 6. To assign the IR bands to vibrational modes, we examined the modes and frequencies observed in similar compounds [40-42]. Infrared spectroscopy was used to verify the functional groups present in the crystal. In the highfrequency region, spreading from 3600 to $2100 \mathrm{~cm}^{-1}$, correspond to the stretching vibrations of the $\mathrm{OH}, \mathrm{NH}, \mathrm{NH}_{2}, \mathrm{CH}_{2}$ and $\mathrm{CH}_{3}$ groups interconnected by a system of hydrogen bonds in the crystal. In addition, the strong and broad signal centered at around $3533 \mathrm{~cm}^{-1}$, assignable for the $\mathrm{OH}$ stretching vibration, indicates the presence of water in the title compound. Weak hydrogen bonds are manifested in the vibrational spectrum such as $\mathrm{N}-\mathrm{H} . . \mathrm{Cl}, \mathrm{C}-\mathrm{H} . . \mathrm{Cl}$ and NH...O as perturbed $\mathrm{NH}^{+}$and $\mathrm{NH}_{2}{ }^{+}$groups vibrations of the deprotonated piperazinium cations and $\mathrm{O}-\mathrm{H}$ groups of water molecules. Moreover, the intense IR band located at $1616 \mathrm{~cm}^{-1}$, 
correspond to the deformation modes $\delta(\mathrm{NH})$ and $\delta(\mathrm{OH})$. The deformation modes of the groups $-\mathrm{CH}_{2}$ and $-\mathrm{CH}_{3}$ and the stretching mode of the bond $\mathrm{C}-\mathrm{N}$ are assigned to bands located between 1500 and $1300 \mathrm{~cm}^{1}$. The bands with frequency at $1111,1085,1007$ and $928 \mathrm{~cm}^{-1}$ are ascribed for the $\delta(\mathrm{C}-\mathrm{N}), v(\mathrm{C}-\mathrm{C}), \delta(\mathrm{C}-\mathrm{H})$ and $\delta(\mathrm{N}-\mathrm{H})$ respectively. Finally, infrared bonds observed in the $600-764 \mathrm{~cm}^{-1}$ range are due to the $\mathrm{CCN}$ and $\mathrm{CNC}$ deformation vibration angles.

DFT calculations showed that the inorganic entities lead to vibrations below $500 \mathrm{~cm}^{-1}$ which are not observed experimentally under our conditions. After optimization of the positions of the protons, we therefore only focused on the vibrations of the equatorial and axial conformer organic cations. These spectra are based on the conformations optimized at the B31YP/CC-pVTZ level of theory. As we can see in Fig. 6, the simulated spectra do not match very well with the observed spectrum of our hydrated complex that contains hydrogen bonds of types $\mathrm{O}-\mathrm{H} \cdots \mathrm{N}$ and $\mathrm{O}-\mathrm{H} \cdots \mathrm{O}$. However, the large bands observed high-frequency region spreading from 3600 to $3000 \mathrm{~cm}^{-1}$ must therefore result from correspond to the stretching vibrations of the $\mathrm{OH}, \mathrm{NH}$ and $\mathrm{NH}_{2}$ groups interconnected by a system of hydrogen bonds. It is worth noting that no band related to free $\mathrm{O}-\mathrm{H}$ stretching and deformation modes $\delta(\mathrm{OH})$ is seen in the simulated spectra. Then, the signals corresponding to $\mathrm{O}-\mathrm{H} \cdots \mathrm{N}$ and $\mathrm{O}-$ $\mathrm{H} \cdots \mathrm{O}$ hydrogen bonds stretching only are observed in experimental spectrum and the absence of this characteristic is accompanied by the absence of overlap and spread signals attributed to the stretching vibrations of the $\mathrm{NH}$ groups.

\subsection{Raman spectroscopy of $\left(\mathrm{C}_{5} \mathrm{H}_{14} \mathrm{~N}_{2}\right)_{2}\left[\mathrm{SnCl}_{6}\right]_{2} .5 \mathrm{H}_{2} \mathrm{O}$ :}

The Raman spectrum of the title compound recorded at low frequencies between 100 and $500 \mathrm{~cm}^{-1}$ is shown in Fig. 7. Based essentially on comparison with the literature for numerous hexachloridostannate (IV) compounds [43,44], it is found that all bands originating from vibrations of $\left.\mathrm{SnCl}_{6}\right)^{2-}$ anions are observed below $350 \mathrm{~cm}^{-1}$. Moreover, the isolated $\left(\mathrm{SnCl}_{6}\right)^{2-}$ anion possesses ideally $\mathrm{O}_{\mathrm{h}}$ symmetry, then, will have six fundamental vibrations. Thus The internal vibrational modes of the free $\left(\mathrm{SnCl}_{6}\right)^{2-}$ anion in $\mathrm{O}_{\mathrm{h}}$ symmetry are classified as:

$$
1 A_{1 g}(R a)+1 E_{g}(R a)+1 F_{2 g}(R a)+2 F_{1 u}(I R)+1 F_{2 u}(I R) \text {. }
$$

Betwen these modes, only the $F_{1 u}\left(v_{3}, 303 \mathrm{~cm}^{-1}\right)$ and $F_{2 u}\left(v_{4}, 166 \mathrm{~cm}^{-1}\right)$ are infrared active while the modes $A_{1 \mathrm{~g}}\left(v_{1}, 311 \mathrm{~cm}^{-1}\right), \mathrm{E}_{\mathrm{g}}\left(v_{2}, 229 \mathrm{~cm}^{-1}\right)$ and $\mathrm{F}_{2 \mathrm{~g}}\left(v_{5}, 158 \mathrm{~cm}^{-1}\right)$ are Raman observable. Thus, the strong band observed in Raman spectrum at $307 \mathrm{~cm}^{-1}$ is assigned to the $(\mathrm{Sn}-\mathrm{Cl})$ asymmetric stretching $\left(v_{1}(\mathrm{Sn}-\mathrm{Cl})\right)$, while the symmetric stretching $\left(v_{2}(\mathrm{Sn}-\mathrm{Cl})\right)$ 
vibration appears as a shoulder band at $223 \mathrm{~cm}^{-1}$. The bending vibration in the plan $v_{5}(\mathrm{Cl}-\mathrm{Sn}$ $\mathrm{Cl}$ ) is located in Raman at $158 \mathrm{~cm}^{-1}$, in fact it is relatively confused at its fundamental value.

In order to attribute the Raman bands, the spectrum was calculated by the same method than the IR wavenumbers interesting only in the internal modes of inorganic anions. There is a very good agreement between the experimental and the theoretical values calculated of the position of the bands, allowing unambiguously the attribution of the different Raman signals (Fig. 7).

\subsection{Optical properties}

\section{UV absorption properties}

The UV and visible spectroscopy is used to detect the presence of chromophores in the molecule. The theoretical and experimental UV-Vis absorption spectra of this eccentric compound are shown in Fig. 8. Taking into account that the title compound exhibits only strong absorption centered at $290 \mathrm{~nm}(4.28 \mathrm{eV})$ a wide literature review was conducted of similar materials to explain the origin of this band. Thereby, we can assign this absorption to the exciton emission of inorganic layers of $\left[\mathrm{SnCl}_{6}\right]^{2-}$ or to ligand to metal charge transfer transition (LMCT) which is very similar to those found in other previous studies of hybrid compounds [45-47].

The pace of this spectrum is observed too much in the theoretical TD/B3LYPUV-Vis absorption spectrum. Indeed, in the UV region of the theoretical UV-Vis absorption spectrum, only maximum absorption at $273 \mathrm{~nm}$ is observed with a shift of $17 \mathrm{~nm}$ compared to the single band observed on the experimental spectrum. Thus, the precision is well-sufficient to assign the experimental absorption and to confirm the attribution proposed above.

\section{Photoluminescence}

The photoluminescence spectrum given in Fig. 9, shows one band of luminescence located at $600 \mathrm{~nm}$ when excited at $222 \mathrm{~nm}$. The excitation by charge transfer from the metal centers to the ligands is commonly observed in $\mathrm{d}^{10}$. However, MOFs with transition-metal ions without unpaired electrons, especially those having $\mathrm{d}^{10}$ configurations like that the tin (IV) ion, can yield linker-based highly emissive materials. Under excitation of these materials an electron is excited from the valence band (VB) to the conduction band (CB), leaving a hole in the VB. In this tin chloride based hybrid, depending on the tin's electronic configuration 
and linker orbital energies, the lowest exciton state arises from excitation between the VB and the $\mathrm{CB}$ bands [45]. We can conclude that the luminescence originates from electronic transition within the inorganic part $\left[\mathrm{SnCl}_{6}\right]$ in this compound.

\section{Quantum mechanical study (HOMO-LUMO)}

The band gap energy is a critical parameter in determining the kinetic stability of the molecule. In our compound, the HOMO and LUMO orbitals were determined for the cations/anions system corresponding to the ions in the asymmetric unit. The highest occupied molecular orbital (HOMO) and the lowest occupied molecular orbital (LUMO) of the molecule are displayed in Fig. 10.Thus as shows this graph, the highest occupied orbitals are localized on the around the mineral anion of the crystal, while the components of the lowest unoccupied orbitals mainly located over the crystallization water molecule and over imino groups of the piperazine ring [41]. The gap between the LUMO and the HOMO is $4.7 \mathrm{eV}$, a value which is relatively large, implies a high kinetic stability and a low chemical reactivity, because it is energetically unfavorable to add electron to a LUMO high and extract the electrons from the low-HOMO [47].

\subsection{Thermal analysis}

The results of the DSC, DTA and TGA measurements carried out to characterize the thermal stability of the complex $\left(\mathrm{C}_{5} \mathrm{H}_{14} \mathrm{~N}_{2}\right)_{2}\left[\mathrm{SnCl}_{6}\right]_{2} .5 \mathrm{H}_{2} \mathrm{O}$ are given in Fig. 11 and Fig. 12 . An overview of the results unambiguously illustrates the existence of only one mass loss in the TG curve of this compound, while the DTA thermogram reveals the presence of three endothermic peaks located at 350, 452 and $482 \mathrm{~K}$, as well as the DSC thermogram reveals three endothermic peaks at $\mathrm{Ta}=332 \mathrm{~K}, \mathrm{~Tb}=446 \mathrm{~K}$ and $\mathrm{Tc}=491 \mathrm{~K}$ in heating and only one exothermic peak at $\mathrm{Td}=491 \mathrm{~K}$ in cooling. This compound seems to be stable up to $300 \mathrm{~K}$. From there, the TG thermogram clearly shows that in the temperature range of 332-363 K a weight loss is observed. Besides, our compound decomposes in a single weight loss in the temperature range of $300-500 \mathrm{~K}$ which is is assigned to loss of the water molecules: ca. $10 \%$ correspond to five moles of water per mole of the compound. The dehydration phenomenon is well confirmed by the presence of the two endothermic anomalies at $\mathrm{T} 1=350 \mathrm{~K}$ and $\mathrm{Ta}=332$ $\mathrm{K}$ respectively in the TDA and DSC thermograms. Afterward the obtained anhydrous phase undergoes other phenomena represented by two additional endothermic peaks shown in the DSC and the DTA thermograms. The endothermic peak located at $\mathrm{T} 2=452 \mathrm{~K}$ in DTA thermogram and the endothermic anomaly locatedat $\mathrm{Tb}=446 \mathrm{~K}$ in DSC thermogram may be 
confirms phase transition phenomenon. The phase transition enthalpy calculated from the endothermic peak area(b) is $\Delta \mathrm{H}_{\mathrm{b}}=11.1027 \mathrm{~J}_{\mathrm{g}} \mathrm{g}^{-1}$. Moreover, the second endothermic peak observed in DTA thermogram at $\mathrm{T} 3=482 \mathrm{~K}$ can be assigned to a second phase transition of this anhydrous phase. Indeed, in the heating/cooling cycle of this compound, endothermic and exothermic reversible anomalies appear at 478 and $491 \mathrm{~K}$, respectively, which confirms the occurrence of a reversible phase transition. The sharp-shaped of the observed exothermic anomalie and the large value of heat hysteresis $\sim 13 \mathrm{~K}$ indicates a typical first-order reversible phase transition. The phase transition enthalpy accompanies this endothermic phenomenon is

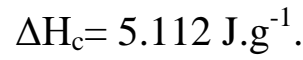

\subsection{XPS analysis}

X-ray photoelectron spectroscopy (XPS) allowed to identify the chemical nature of the species present on the surface of this $\left(\mathrm{C}_{5} \mathrm{H}_{14} \mathrm{~N}_{2}\right)_{2}\left[\mathrm{SnCl}_{6}\right]_{2} .5 \mathrm{H}_{2} \mathrm{O}$, more particularly important in determining the oxidation state of the tin. This compound was dried under vacuum and tested by XPS. By sweeping the energy of the analyzer from 0 to $1000 \mathrm{eV}$ in binding energy, the spectrum of XPS survey scans is obtained and shows in Fig. 13. At each recorded peak corresponds a binding energy which is specific to an oxidized species. The main peaks of the elements present on the surface of $\left(\mathrm{C}_{5} \mathrm{H}_{14} \mathrm{~N}_{2}\right)_{2}\left[\mathrm{SnCl}_{6}\right]_{2} .5 \mathrm{H}_{2} \mathrm{O}$ compound films are decoupled at creasing order energy as follows: $\mathrm{Cl} 2 \mathrm{p}, \mathrm{C} 1 \mathrm{~s}, \mathrm{~N} 1 \mathrm{~s}, \mathrm{Sn} 3 \mathrm{~d}$ and $\mathrm{O} 1 \mathrm{~s}$ centered respectively at $197.55 \mathrm{eV}, 285.8 \mathrm{eV}, 402.1 \mathrm{eV}, 486.33 \mathrm{eV}$ and $532.46 \mathrm{eV}$. The X-ray photoelectron spectroscopy measurements were carried out in the energy region of $\operatorname{Sn} 3 d_{5 / 2}$ and $\operatorname{Sn} 3 d_{3 / 2}$ respectively. Fig. 14 show that the $\mathrm{Sn} 3 \mathrm{~d}_{5 / 2}$ region exhibited a single feature at a binding energy of $486.3 \mathrm{eV}$, confirming that the sample was composed of only $\mathrm{Sn}(\mathrm{IV})$ states [48-50]. Quantitative analysis of the spectrum over flight provided information about the binding energy and the atomic percentage of the different elements detected. (Table. 4.).

\section{Experimental details}

\subsection{Synthesis of the $\left(\mathrm{C}_{5} \mathrm{H}_{14} \mathrm{~N}_{2}\right)_{2}\left[\mathrm{SnCl}_{6}\right]_{2.5} \mathrm{H}_{2} \mathrm{O}$ compound}

The single crystal of $\left(\mathrm{C}_{5} \mathrm{H}_{14} \mathrm{~N}_{2}\right)_{2}\left[\mathrm{SnCl}_{6}\right]_{2} .5 \mathrm{H}_{2} \mathrm{O}$ was first prepared by an acid-base reaction between hydrochloric acid $(10 \mathrm{~mL}, 1 \mathrm{M}), \mathrm{SnCl}_{2}\left(10^{-3} \mathrm{~mol}\right)$ and 1-methylpiperazine in the presence of ethanol $(10 \mathrm{~mL})$ in a stoichiometric ratio 1:1.

The elemental analysis method was applied to determine the proposed formula of the the obtained crystals : 
N, 5.92\%/5.85\% (exp/theor); C, 12.59\%/12.53\%; H, 4.01\%/3.96\%.

The chemical reaction scheme is:

$$
2 \mathrm{C}_{5} \mathrm{H}_{12} \mathrm{~N}_{2}+2 \mathrm{SnCl}_{2}+8 \mathrm{HCl}+\mathrm{H}_{2} \mathrm{O} \rightarrow\left(\mathrm{C}_{5} \mathrm{H}_{14} \mathrm{~N}_{2}\right)_{2}\left[\mathrm{SnCl}_{6}\right]_{2} .5 \mathrm{H}_{2} \mathrm{O}
$$

\subsection{Characterization}

The characterization of the prepared compound was performed using X-ray monocristal diffraction, X-ray powder diffraction, Hirshfeld Surface Analysis, IR and Raman spectroscopy, UV-Vis spectrophotometry, photoluminescence analysis and differential Scanning Calorimetry measurements.

\subsubsection{X-ray diffraction studies}

A suitable colorless crystal of the title compound was chosen for the structure determination and refinement. Indeed, single crystals were carefully selected under a microscope and mounted on a Mitegen micromesh mount with the help of a trace of mineral oil. The crystal structure was determined from the single-crystal X-ray diffraction data collected at room temperature using Oxford Diffraction Xcalibur GeminiS diffractometer equipped with MoK $\alpha$ radiation $(0.71073 \AA)$. The positional parameters for the heavy atoms were obtained from a three-dimensional Patterson map, while the non-hydrogen atoms were found from successive difference Fourier Maps. Then, the structure was refined by fullmatrix, all non hydrogen atoms were refined anisotropically. Well as all the hydrogen atoms positions were placed geometrically and refined isotropically. The structure analyses were carried out with the orthorhombic symmetry, space group $P 2{ }_{1}{ }_{1}{ }_{2}{ }_{1}$, according to the automated search for space group available in WinGX [17]. The Tin atom was located using the Patterson methods with program SHELXS-97[18]. The oxygen atoms and the organic moieties were found from successive Fourier calculations using SHELXL-97. Crystal data are reported in Table 1. Drawings were made with Mercury [19] for Fig. 1 and Diamond [20] for figs. 2 and 3.

The visualization and exploration of the intermolecular close contacts of the structure was achieved by calculating the Hirshfeld surface with the Crystal Explorer software [21]. All the bond lengths to hydrogen were automatically modeled to typical standard neutron values $(\mathrm{C}-\mathrm{H}=1.083 \AA$ and $\mathrm{N}-\mathrm{H}=1.009 \AA)$. In this study, the molecular Hirshfeld surfaces were 
generated using a standard (high) surface resolution with the 3D dnorm surfaces mapped over a fixed color scale from $0.42 \AA$ (red) to $1.6 \AA$ (blue). The 2-D finger print plots were displayed by using the standard range $0.6-2.8 \AA$.

Quantum chemical calculation was performed with gaussian09w software [22] from the crystal data using the B31YPfunctional [23] and LANL2DZdp basis set in Sn atom with LANL2DZdp ECP [24-28] and the cc-PVTZ [29] basis sets in other atoms. The D3 version of Grimme's dispersion correction [30] was added to predict weak interactions between molecules.

\subsubsection{IR, Raman, UV and XPS measurements}

Fourier Transform Infrared (FTIR) spectra of powder samples were obtained using a 1000 Perkin-Elmer FTIR spectrometer from potassium bromide $(\mathrm{KBr})$ pellets. The IR spectra were recorded in the $4000-400 \mathrm{~cm}^{-1}$ range and the Raman spectrum was recorded between 500 and $100 \mathrm{~cm}^{-1}$ at room temperature with a LABRAMHR 800 triple monochromatic instrument using a $514.5 \mathrm{~nm}$ line spectra physics argon ion laser on the other hand the UV absorption and optical diffuse reflectance spectra were measured at room temperature with a Perkin Elmer Lambda 11UV/ Vis spectrophotometer in the 200-700 nm range and the Solid photoluminescence spectra were recorded using a time-resolved Edimbugh Instruments FLSP920 spectrofluorimeter with a Red-PMT detector and a Xenon bulb as an excitation source Finally the measurements XPS data were carried out using an XPS-ESCALAB 250 apparatus of VG with a double anode Al. Only the Al Ka radiation with energy of $1253.6 \mathrm{eV}$ was used since it allows a better resolution some pics. The pass energy was set to 200 and 50 $\mathrm{eV}$ respectively for the survey and the narrow regions. Electron and argon flood guns were used to compensate for the static charge build up of the powders. The composition was determined using the manufacturer sensitivity factors.

\subsubsection{Thermal analysis}

The thermogravimetric and differential thermal analyses were coupled using TGA Q500 TA instrument, by putting the powder sample (about $28.5426 \mathrm{mg}$ for a scanning rate of

$\left.5 \mathrm{~K} \mathrm{~min}^{-1}\right)$ in aluminum capsule. The powder sample $(28.5426 \mathrm{mg})$ was studied in the temperature range from 300 to $600 \mathrm{~K}$ under inert atmosphere (nitrogen gas). The differential scanning calorimetric (DSC) measurements were made on a SETARAM DSC131 ks 
instrument. A powder sample was heated from $300 \mathrm{~K}$ to $525 \mathrm{~K}$ with a ramp rate of $5 \mathrm{c} \cdot \mathrm{min}^{-1}$ under dynamic argon atmosphere.

\section{Conclusion}

Attempts have been made in the present work for the preparation and the physicochemical characterization of a new $\left(\mathrm{C}_{5} \mathrm{H}_{14} \mathrm{~N}_{2}\right)_{2}\left[\mathrm{SnCl}_{6}\right]_{2} .5 \mathrm{H}_{2} \mathrm{O}$ compound. Single crystal X-ray diffraction, FTIR, FT-Raman spectra, optical study, thermal analyses and X-ray photoelectron spectroscopy. Single crystal X-ray diffraction showed that the title compound composed of alternating inorganic and organic layers. The crystal structure was stabilized by intermolecular H-bonding. The Hirschfeld surfaces certainly allow a much more detailed scrutiny by displaying all the intermolecular interactions within the crystal and this methodology has very important promise in crystal engineering such as the fingerprint plot than provides the information about the percentage contribution and revealed that the $\mathrm{H} \cdots \mathrm{Cl}$ (63.3\%) and $\mathrm{H} \cdots \mathrm{H}(23.2 \%)$ interactions constitute the driving force in the crystal packing. We have also calculated the vibrational frequencies of this compound by using B3LYP method. The fundamental vibrations obtained by the both theoretical and experimental methods in FT-IR and FT-Raman spectra are in good agreement. Moreover, the studies of optical and photoluminescence activities prove that this compound exhibits high stability and reveals the free character of the inorganic exciton. The calculations show that using TD-DFT approach, experimental absorption spectrum has been well reproduced. The (TGA/DTA/DSC) thermal analyses were performed to establish the thermal stability of the crystal. This thermal study shows two transitions phases. Future research projects will investigate other hybrid materials.

\section{Supplementary data}

Supplementary crystallographic data for this article in CIF format are available at the Electronic Supplementary Publication from Cambridge Crystallographic Data Centre (CCDC 1560010). This data can be obtained free of charge via http://www.ccdc.cam.ac.uk/conts/retrieving.html, from the Cambridge Crystallographic Data Centre, 12 Union Rood, Cambridge CB2 1EZ, UK (Fax: (international): +44 1223/336 033; email: deposit@ ccdc.cam.ac.uk). Projection along the b-axis showing the organic-inorganic layers in the title compound crystal, relative contributions to the Hirshfeld surface areas for 
the various intermolecular contacts, are given in Fig S1-S2 and selected bond distances and angles in $\left(\mathrm{C}_{5} \mathrm{H}_{14} \mathrm{~N}_{2}\right)_{2}\left[\mathrm{SnCl}_{6}\right]_{2} .5 \mathrm{H}_{2} \mathrm{O}$ and Surface composition (in atomic \%) are given in Table $\mathrm{S} 1$ and $\mathrm{S} 2$.

\section{Acknowledgments}

Financial support from Spanish MINECO (MAT2016-78155-C2-1-R, MAT201340950-R, and FPI grant BES-2011-046948 to MSM.A.), GobiernodelPrincipado de Asturias (GRUPIN14-060), FEDER, and the Secretary of State for Scientific Research and Technology of Tunisia, are acknowledged. 


\section{References}

[1] M. Zdanowska-Fraczek, K. Holderna-Natkaniec, Z.J. Fraczek, R. Jakubas, Solid State Ion., 180 (2009) 9-12.

[2] I. Chaabane, F. Hlel, K. Guidara, J. Alloys Compd., 461 (2008) 495-500.

[3] K. Sakai, M. Takemura, Y. Kawabe, J. Lumin., 130 (2010) 2505-2507.

[4] K. Pradeesha, G. SharachandarYadava, M. Singhb, G. Vijaya Prakash, Mater. Chem. Phys., 124 (2010) 44-47.

[5] A. Vishwakarma, P. Ghalsasi, A. Navamoney, Y. Lan, A. Powell, Polyhedron., 30 (2011) 1565-1570.

[6] C. Aruta, F. Licci, A. Zappettini, F. Bolzoni, F. Rastelli, P. Ferro, T. Bezagni, Appl. Phys., A81 (2005) 963-968.

[7] M. Bujak, J. Zaleski, Cryst. Eng., 4 (2001) 241-252.

[8] K. Karoui, A.B. Rhaiem, K. Guidara, Phys. B, 407 (2012) 489-493.

[9] R. Visbal, M. C. Gimeno, Chem. Soc. Rev., 43 (2014) 3551-3574

[10] F. Marchetti, R. Pettinari, C. Pettinari, Coord. Chem. Rev., 303 (2015), 1-31 12

[11] J. Masternak, M. Zienkiewicz-Machnik, M. Kowalik, A. Jablonska-Wawrzycka, P. Rogala, A. Adach, B. Barszcz, Coord. Chem. Rev., 327 (2016) 242-270

[12] R.S. Upadhayaya, N. Sinha, S. Jain, N. Kishore, R. Chandra, S.K. Arora, Bioorg. Med. Chem., 12 (2004) 2225.

[13] W. O. Foye, T.L. Lemke, D.A. William, Principles of Medicinal Chemistry, fourth ed., Williams and Wilkins, London, 1995.

[14] L. L. Gan, Y.H. Lu, C.H. Zhou, Chin. J. Biochem. Pharm., 30 (2009) 127.

[15] J. L. Cai, Y.H. Lu, L.L. Gan, C.H. Zhou, Chin. J. Antibiot., 34 (2009) 454.

[16] L. L. Gan, J.L. Cai, C.H. Zhou, Chin. Pharm. J., 44 (2009) 1361.

[17] L. J. Farrugia, J. Appl. Cryst., 32 (1999) 837-838.

[18] G. M. Sheldrick, SHELXL-97, (1997), Program for Crystal Structure Refinement, University of Gottingen, Germany.

[19] C. F. Macrae, P. R. Edgington, P. McCabe, G. Pidcock, P. Shields, R. Taylor, M. Towler, J. Van de Streek, Mercury: visualization and analysis of crystal structures, J. Appl. Cryst., 39 (2006) 453-457.

[20] K. Brandenburg. (1998), DIAMOND version 2.0.

[21] S. K. Wolff, D. J. Grimwood, J. J. McKinnon, D. Jayatilaka, M. A. Spackman, (2007), CrystalExplorer, Version 1. 5, University of Western Australia, Perth, Australia. 
[22] Gaussian 09, Revision D.01, M. J. Frisch, G. W. Trucks, H. B. Schlegel, G. E. Scuseria, M. A. Robb, J. R. Cheeseman, G. Scalmani, V. Barone, B. Mennucci, G. A. Petersson, H. Nakatsuji, M. Caricato, X. Li, H. P. Hratchian, A. F. Izmaylov, J. Bloino, G. Zheng, J. L. Sonnenberg, M. Hada, M. Ehara, K. Toyota, R. Fukuda, J. Hasegawa, M. Ishida, T. Nakajima, Y. Honda, O. Kitao, H. Nakai, T. Vreven, J. A. Montgomery, Jr., J. E. Peralta, F. Ogliaro, M. Bearpark, J. J. Heyd, E. Brothers, K. N. Kudin, V. N. Staroverov, R. Kobayashi, J. Normand, K. Raghavachari, A. Rendell, J. C. Burant, S. S. Iyengar, J. Tomasi, M. Cossi, N. Rega, J. M. Millam, M. Klene, J. E. Knox, J. B. Cross, V. Bakken, C. Adamo, J. Jaramillo, R. Gomperts, R. E. Stratmann, O. Yazyev, A. J. Austin, R. Cammi, C. Pomelli, J. W. Ochterski, R. L. Martin, K. Morokuma, V. G. Zakrzewski, G. A. Voth, P. Salvador, J. J. Dannenberg, S. Dapprich, A. D. Daniels, O. Farkas, J. B. Foresman, J. V. Ortiz, J. Cioslowski, and D. J. Fox, Gaussian, Inc., Wallingford CT, 2009.

[23] A. D. Becke, J. Chem. Phys., 98 (1993) 5648-52.

[24] Feller, D., J. Comp. Chem., 17(13), 1571-1586, 1996.

[25] Schuchardt, K.L., Didier, B.T., Elsethagen, T., Sun, L., Gurumoorthi, V., Chase, J., Li, J., and Windus, T.L. J. Chem. Inf. Model., 47(3), 1045-1052, 2007.

[26] P. J. Hay, W. R. Wadt, J. Chem. Phys., 82 (1985) 270.

[27] P. J. Hay, W. R. Wadt, J. Chem. Phys., 82 (1985) 284.

[28] P. J. Hay, W. R. Wadt, J. Chem. Phys., 82 (1985) 299.

[29] T. H. Dunning Jr, J. Chem. Phys., 90 (1989) 1007-23.

[30] S. Grimme, J. Antony, S. Ehrlich and H. Krieg, W. R. Wadt, J. Chem. Phys., 132 (2010) 154104.

[31] W. Sondra, N. Houcine, Y. Samia, M. Tahar., Acta Cryst E., 67 (2011) m1605.

[32] Cong-hu. P, Acta Cryst E., 67 (2011) m99.

[33] S. Belhaj Salah, . P.S. Pereira da Silva, F. Lefebvre, C. Ben Nasr, S. Ammar, M.L Mrad., J. Mol. Struct.,1133 (2017) 253-266.

[34] S. Belhaj Salah, . P.S. Pereira da Silva, F. Lefebvre, C. Ben Nasr, S. Ammar, M.L Mrad, J. Mol. Struct., 1137 (2017) 553-561.

[35] P. Krishnan, K. Gayathi, G. Bhagavannarayana, S. Gunasekaran, G. Anbalagan, Growth, J. Spectrochim. Acta Part., A 102 (2013) 379-385.

[36] K. Kaabi, M. Zeller, V. Ferretti, P.S. Pereira Silva, C. Ben Nasr, J. Inorg. Chim. Acta., 388 (2012) 52-59.

[37] S. Karoui, S. Kamoun, Int. J. Sci. Res., 4 (2015) 2201-2210.

[38] I. Mkaouar, N. Karaa, B. Hamdi, J. Mol. Struct., 1115 (2016) 161-170. 
[39] A. C. Dhieb, A. Valkonen, M. Rzaigui, W. Smirani, J. Mol. Struct., 1102 (2015) 5056.

[40] S. Gatfaoui, A. Mezni, T. Roisnel, H. Marouani, J. Mol. Struct., 1139 (2017) 52-59.

[41] S. Soudani, M. Zeller, C. Jelsch, F. Lefebvre, C. Ben Nasr, J. Solid State Chem., 58 (2016) 94-100.

[42] M. Daszkiewicz, J. Mol. Struct., 1032 (2013) 56-61.

[43] M. Daszkiewicz, M. K. Marchewka, J. Mol. Struct., 1017 (2012) 90-97.

[44] M. S. Lassoued, M. S. M. Abdelbaky, R. M. Mero no, A. Gadri, S. Ammar, A. B. Salah, S. García-Granda, J. Mol. Struct., 1142 (2017) 73-79.

[45] M. D. Allendorf, C. A. Bauer, R. K. Bhakta, R. J. T. Houk, Chem. Soc. Rev., 38 (2009) 1330-1352.

[46] A. Maalaoui, B.S. Olfa, S.T. Akriche, S.S. Al-Deyabd, M. Rzaigui, J. Cryst. Struct., $67 b$ (2012) 1178-1184.

[47] M.S. Lassoued, S.M. Abdelbaky, A. Lassoued, R. Mendoza Meroño, S. Ammar, A. Gadri, A. Ben Salah, S. García-Granda, J. Mol. Struct., 03 (2017) 104.

[48] P. G. Antonov, Yu. N. Kukushkin, V.G. Shtrele, Yu. P, Kostikov, F. K. Egrov, Zh, Neorg. Khimili., 27 (1982) 3130.

[49] H . Willemen, D. F. Van De Vondel, G. P. Van Der Kelen., Inorg. Chim. Acta, 34 (1979) 175.

[50] M. Camali, F. Caruso, Inorg. Chim. Acta, 170 (1990) 225. 


\section{Figure captions}

Fig. 1

A view of the asymmetric unit in the crystal structure of the title compound showing the atom-numbering scheme and displacement ellipsoids drawn at the $50 \%$ probability level.

Fig. 2

Projection along the a-axis of the crystal packing of the title compound. The dotted lines indicate hydrogen bonds.

Fig. 3

Projection along the c-axis of the crystal packing of the title compound

Fig. 4

Hirshfeld Surfaces mapped with $\mathrm{d}_{\text {norm }}$ for the title compound.

Fig. 5

The two-dimensional fingerprint plot $(98.7 \%)$ for $\left(\mathrm{C}_{5} \mathrm{H}_{14} \mathrm{~N}_{2}\right)_{2}\left[\mathrm{SnCl}_{6}\right]_{2} .5 \mathrm{H}_{2} \mathrm{O}$, showing contributions from different contacts

Fig. 6

Calculated and experimental IR absorption spectrum of $\left(\mathrm{C}_{5} \mathrm{H}_{14} \mathrm{~N}_{2}\right)_{2}\left[\mathrm{SnCl}_{6}\right]_{2} .5 \mathrm{H}_{2} \mathrm{O}$

Fig. 7

Calculated and experimentalRaman spectrum of the title compound in the [500-100] $\mathrm{cm}^{-}$ ${ }^{1}$ range.

Fig. 8

Superposition of optical absorption spectra measured at room temperature and theoretical DFT UV-Visible spectrum of the title compound.

Fig. 9.

Photoluminescence spectrum of the title compound. 
Fig. 10 .

Frontier molecular orbitals (HOMO and LUMO) of the title compound.

Fig. 11.

DTA/TGA curve for $\left(\mathrm{C}_{5} \mathrm{H}_{14} \mathrm{~N}_{2}\right)_{2}\left[\mathrm{SnCl}_{6}\right]_{2} .5 \mathrm{H}_{2} \mathrm{O}$

Fig.12.

DSC curve for $\left(\mathrm{C}_{5} \mathrm{H}_{14} \mathrm{~N}_{2}\right)_{2}\left[\mathrm{SnCl}_{6}\right]_{2} .5 \mathrm{H}_{2} \mathrm{O}$

Fig. 13.

XPS survey scans of $\left(\mathrm{C}_{5} \mathrm{H}_{14} \mathrm{~N}_{2}\right)_{2}\left[\mathrm{SnCl}_{6}\right]_{2} .5 \mathrm{H}_{2} \mathrm{O}$.

Fig. 14.

High-resolution Sn3d narrow region of the title compound. 


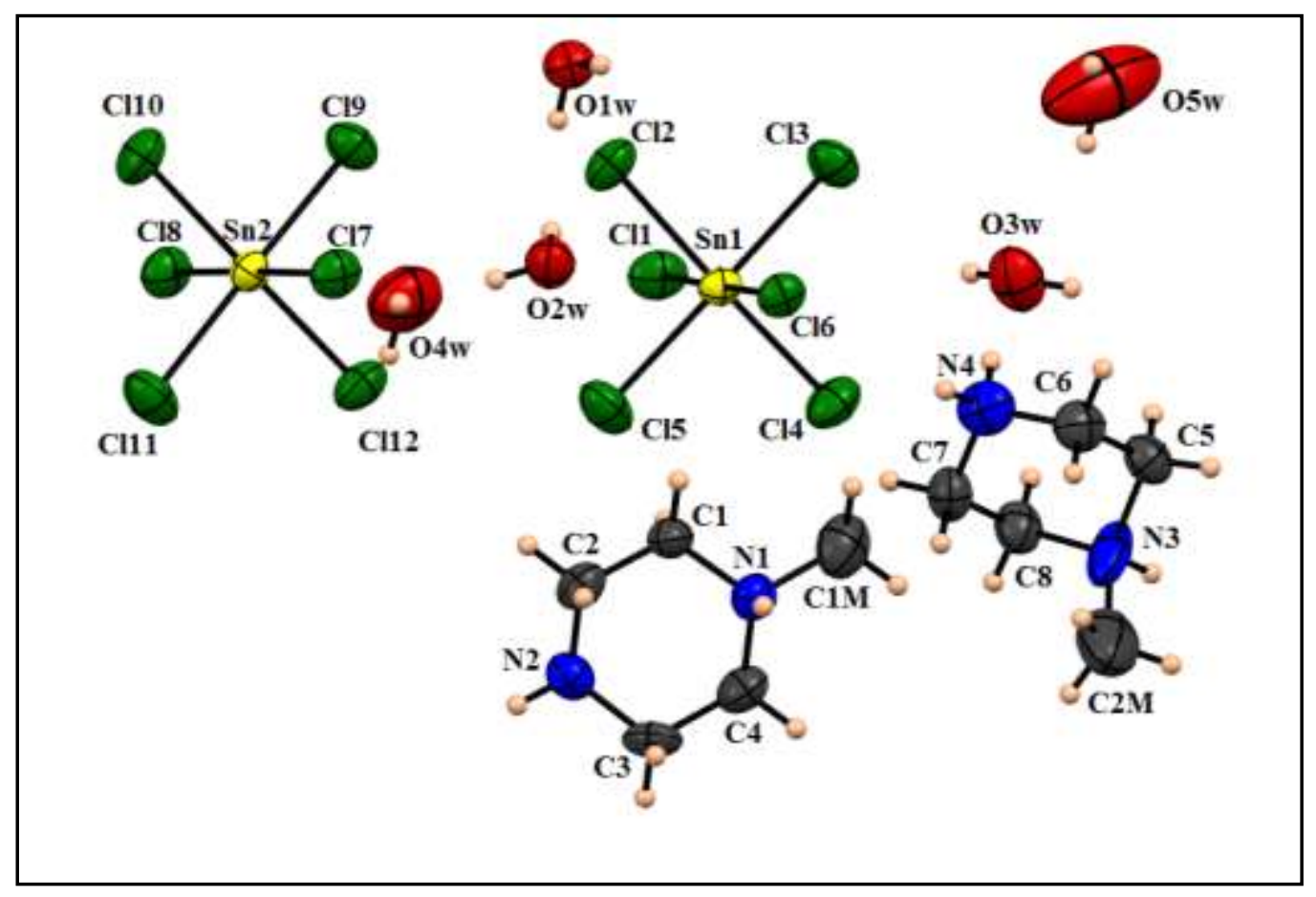

Fig. 1

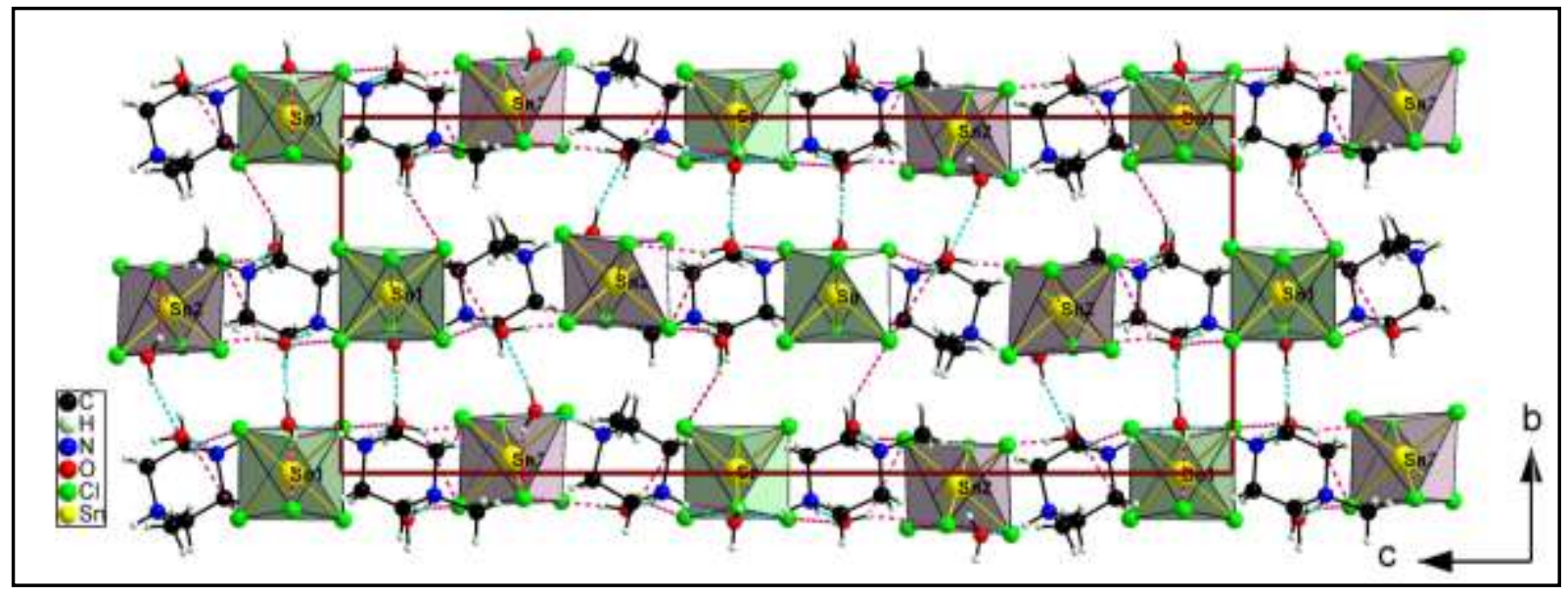

Fig. 2 


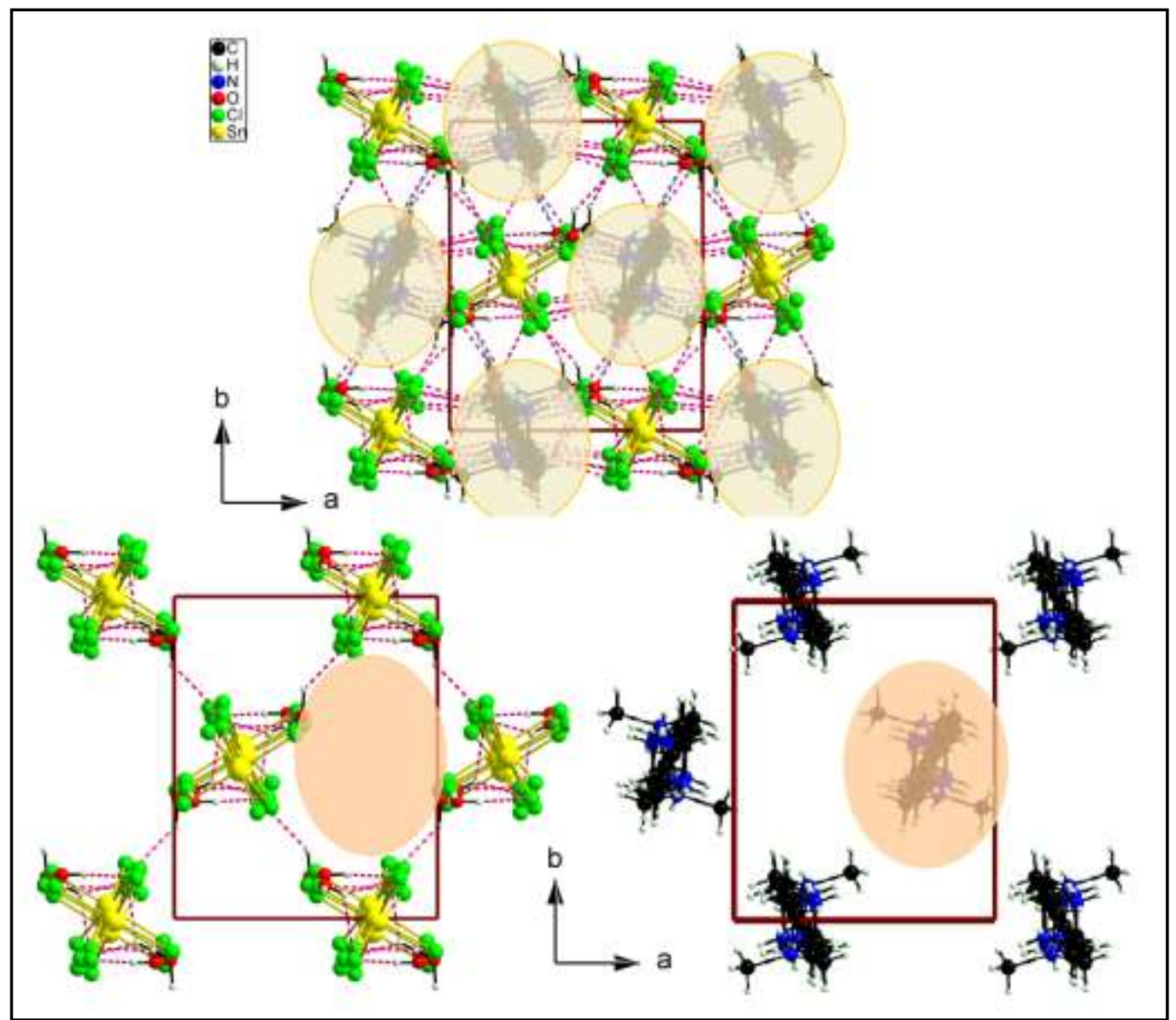

Fig. 3
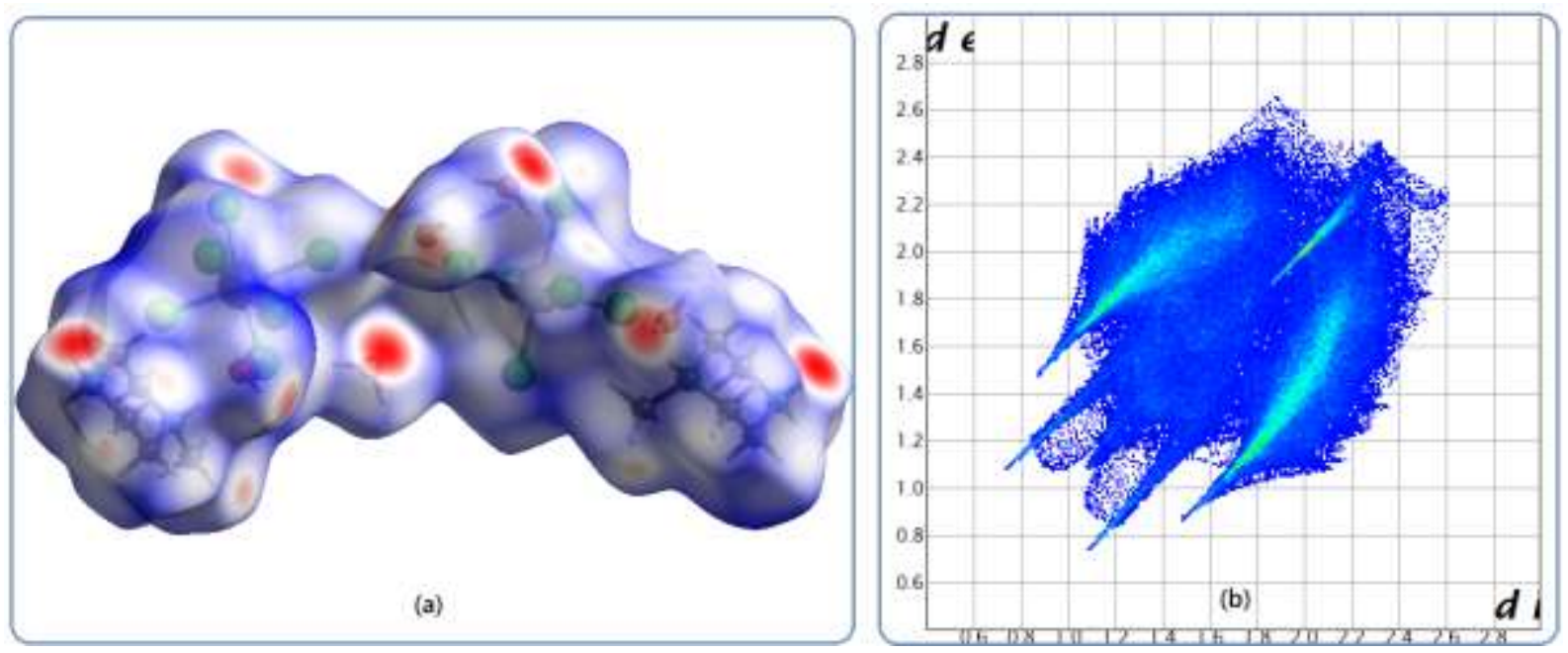

Fig. 4 

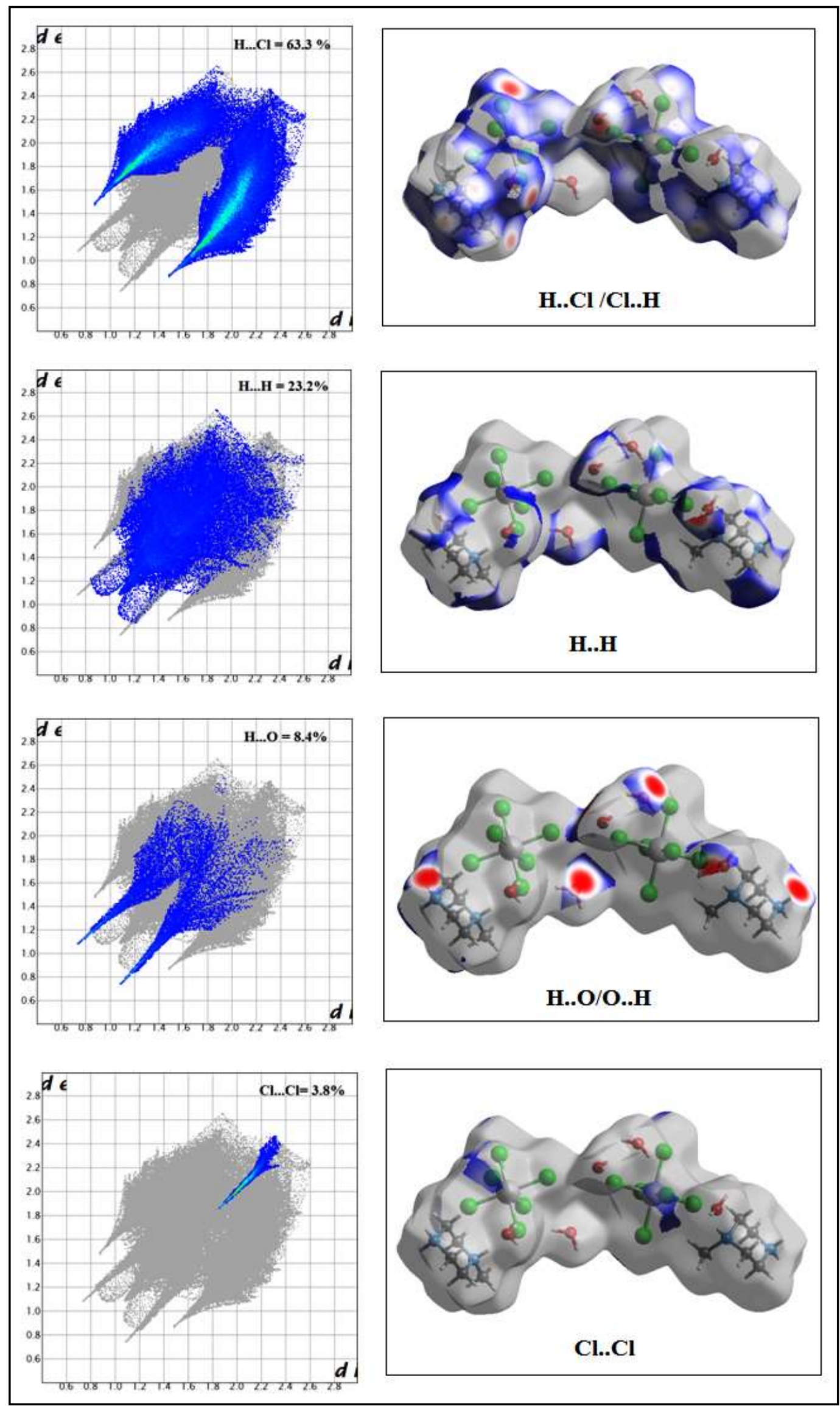

Fig. 5 


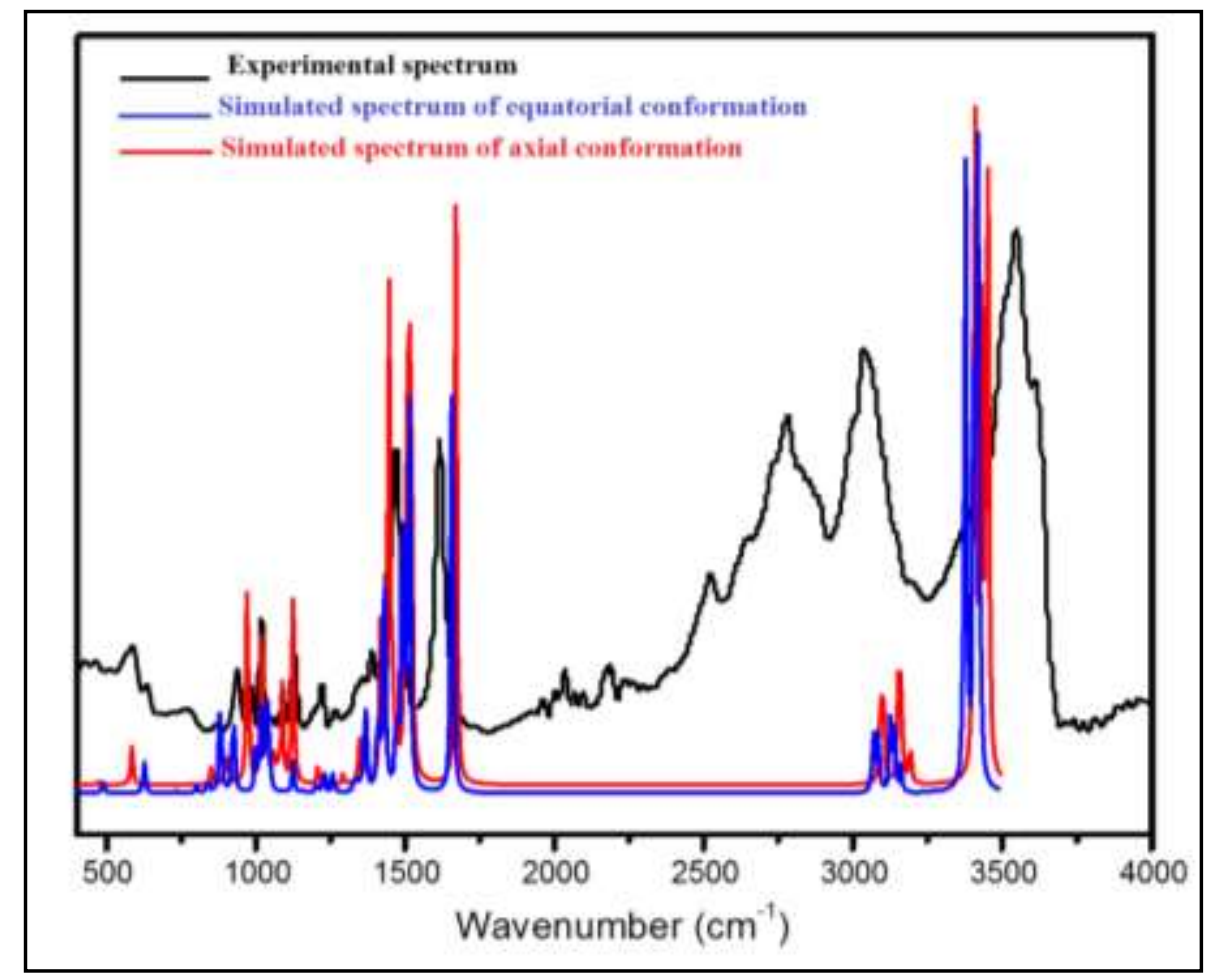

Fig. 6.

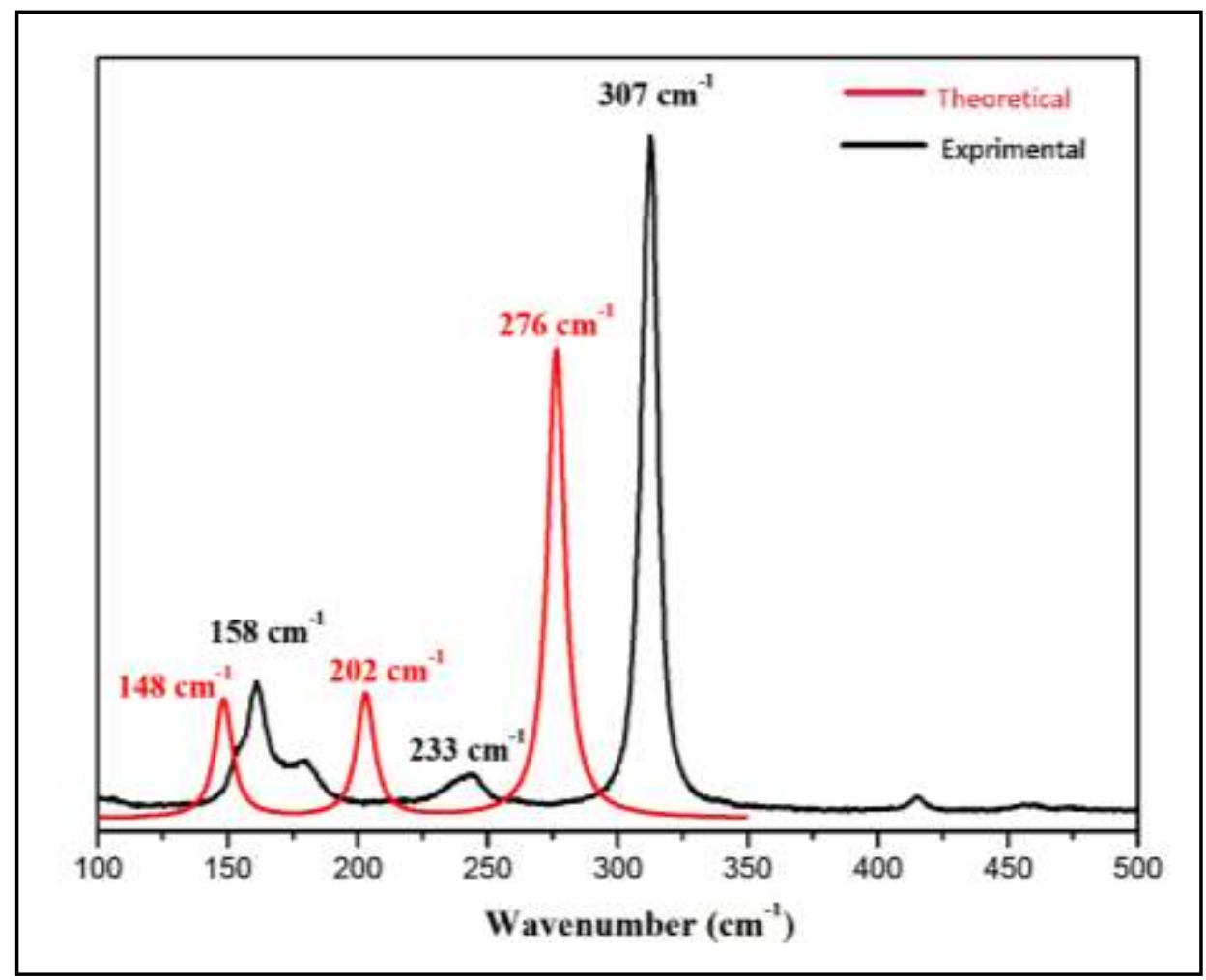

Fig. 7 


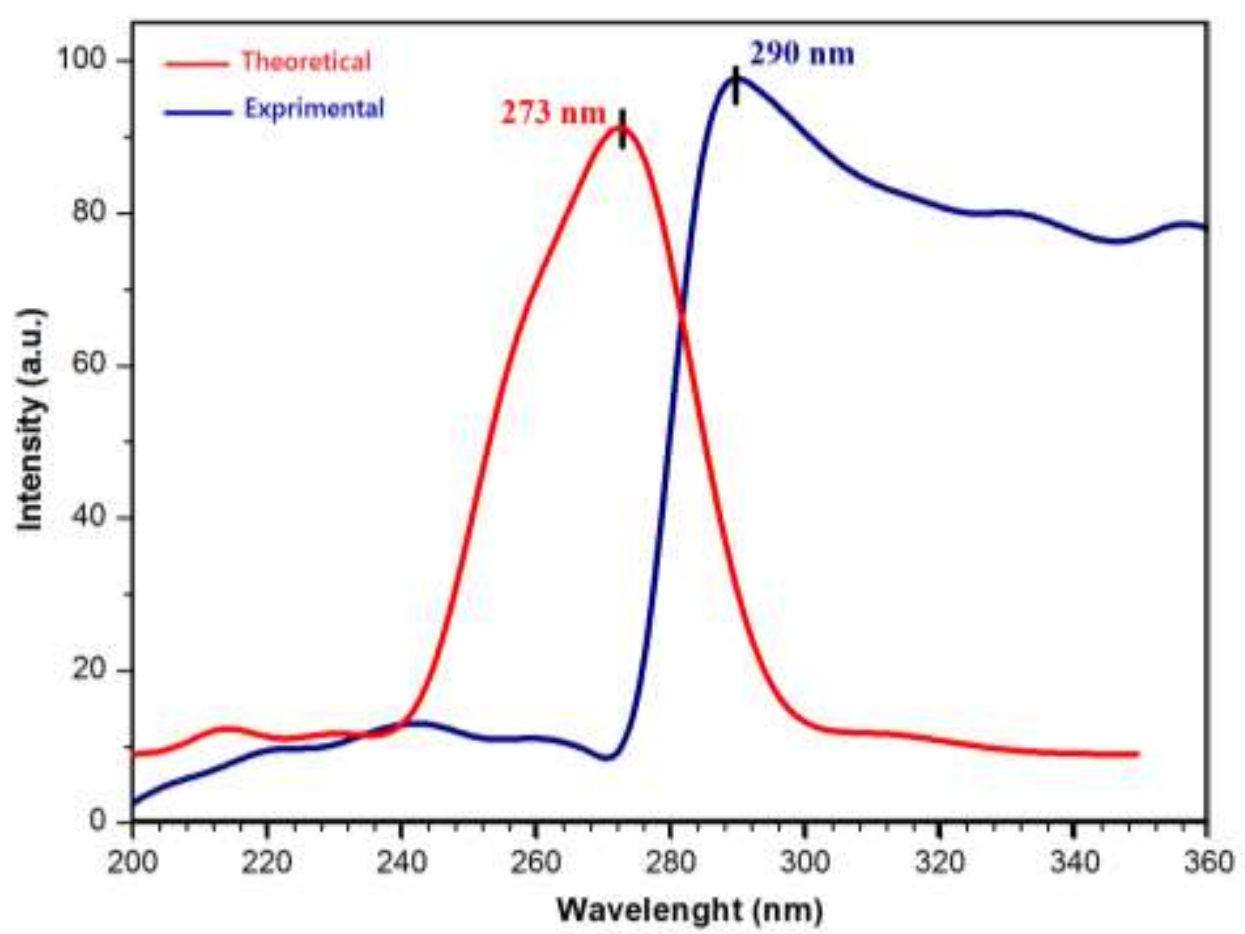

Fig. 8

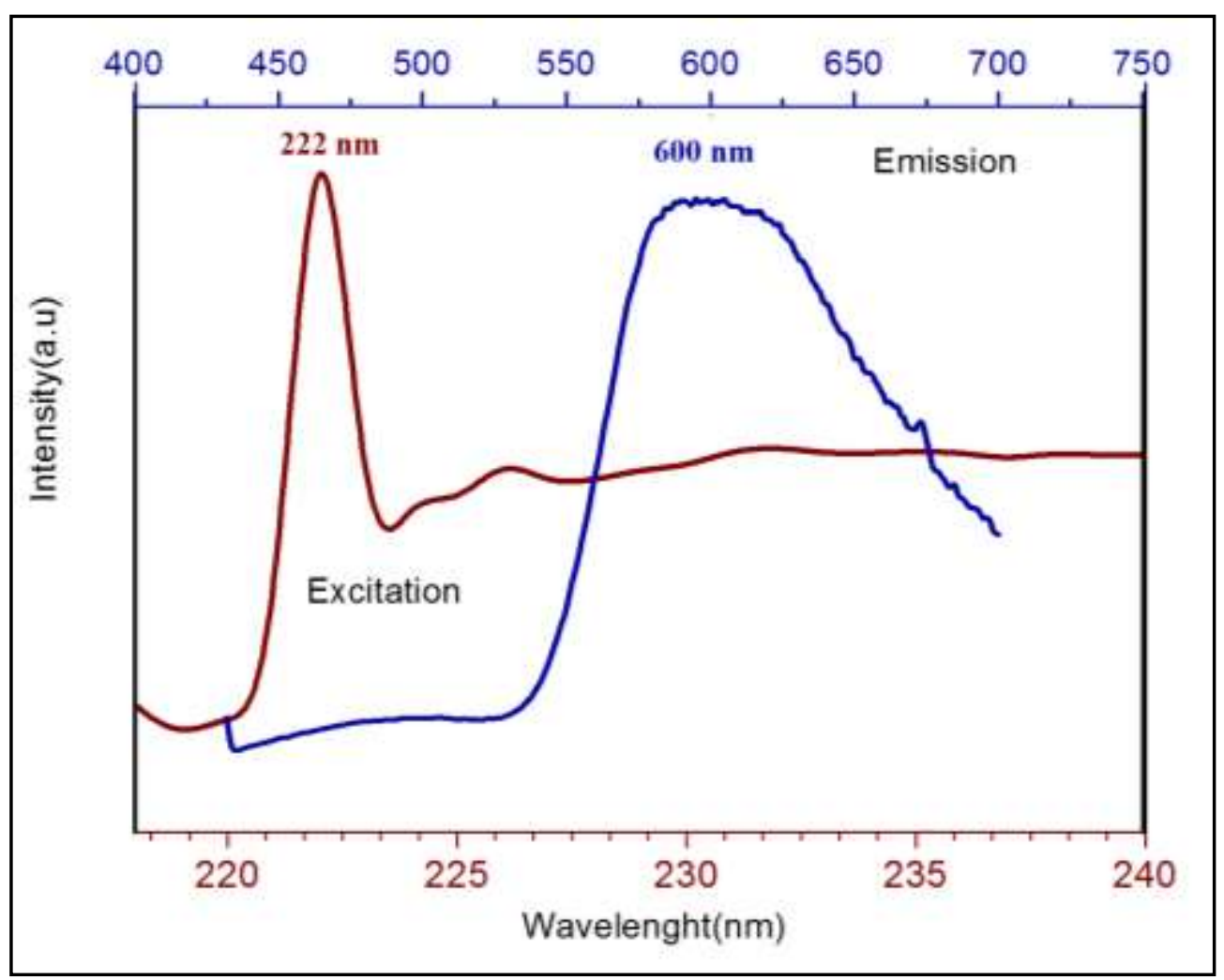

Fig. 9. 


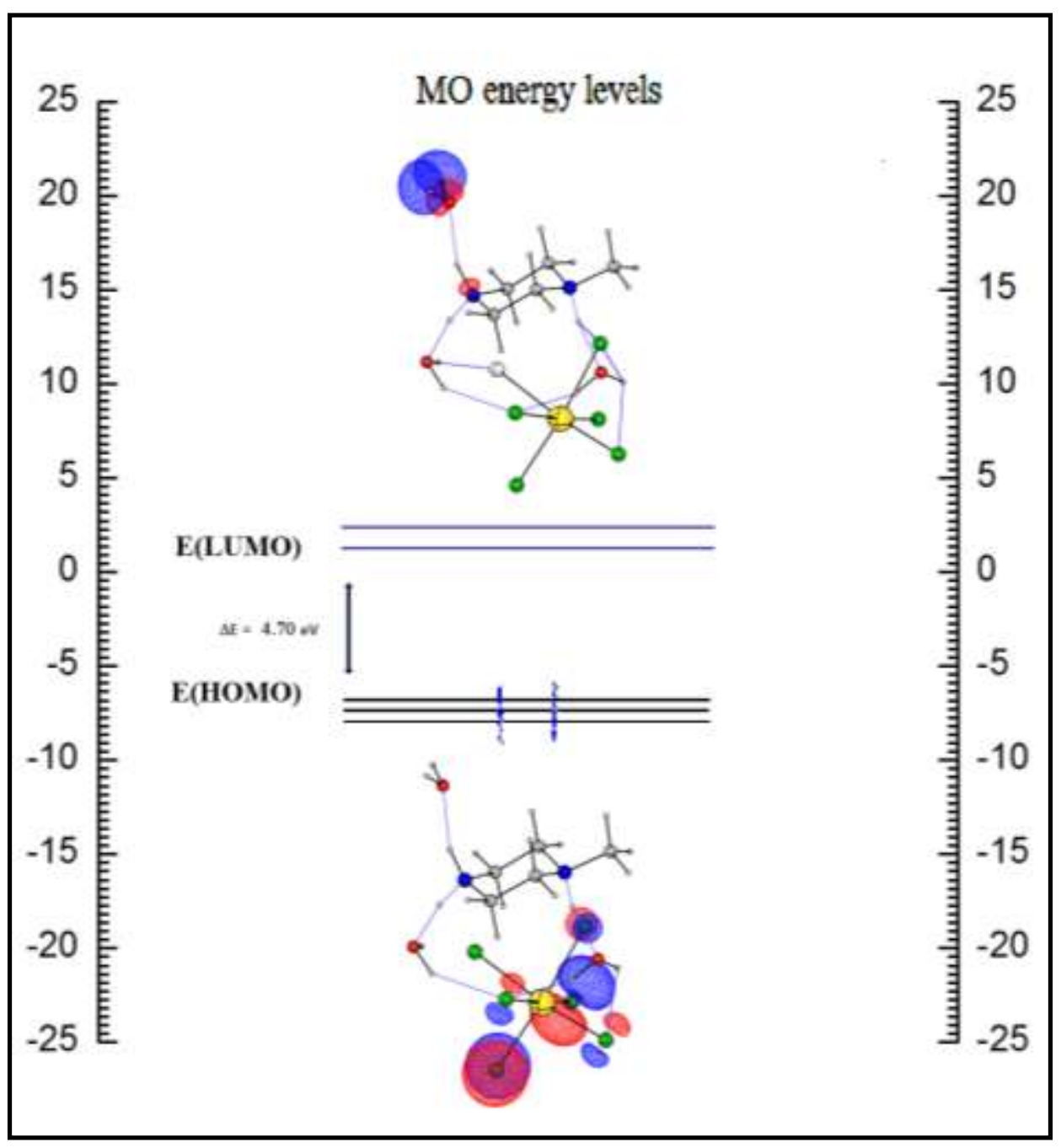

Fig. 10. 


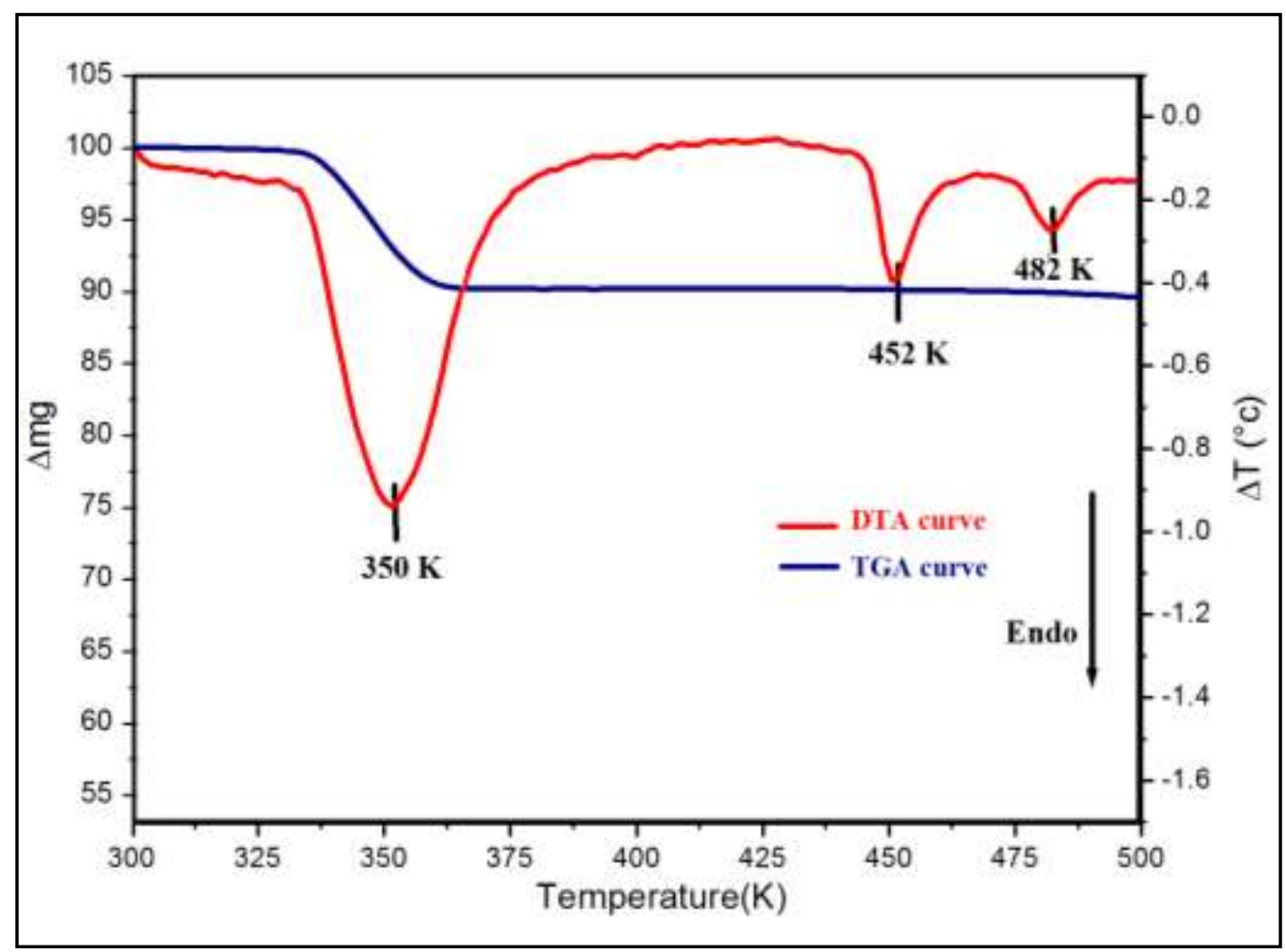

Fig. 11

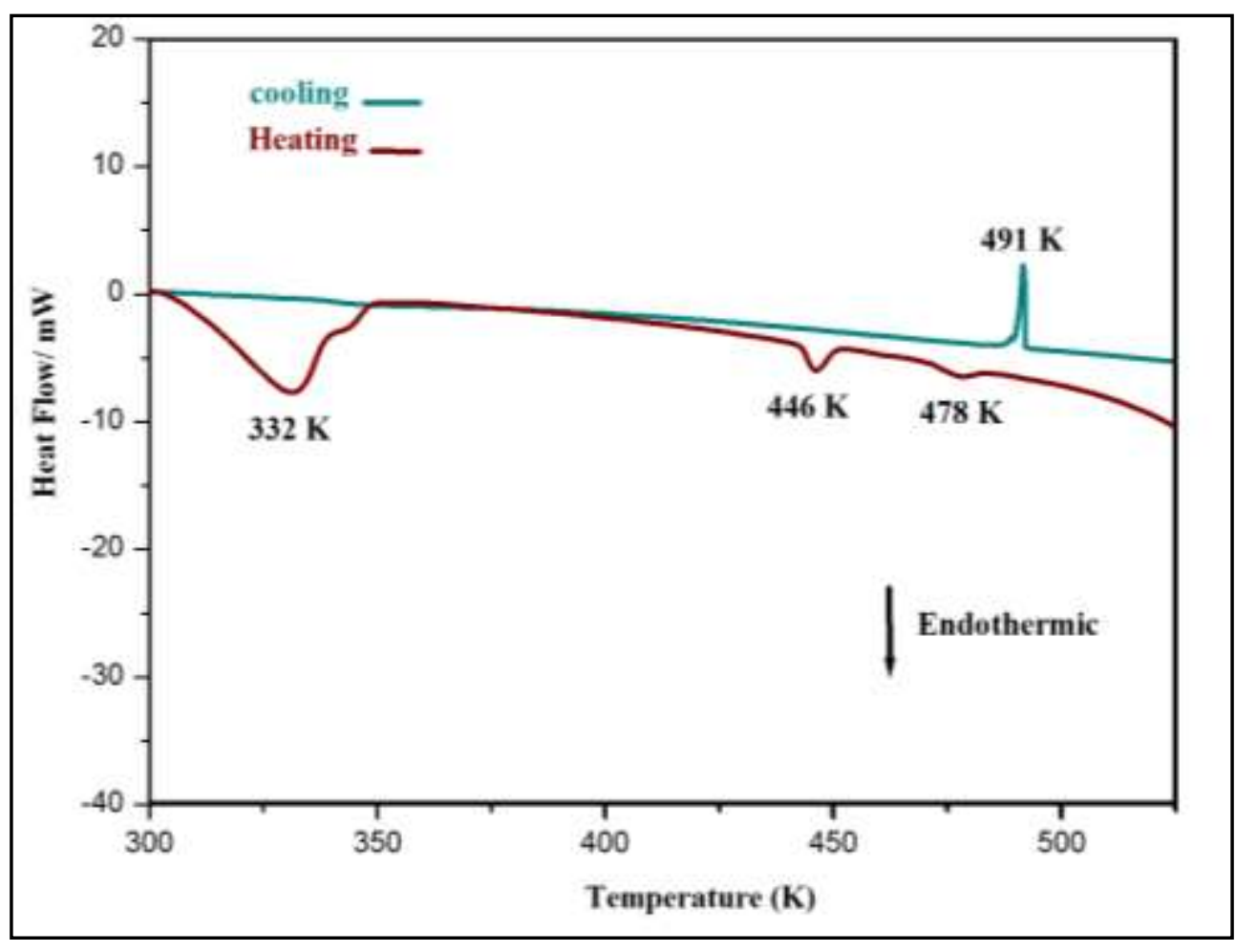

Fig. 12 


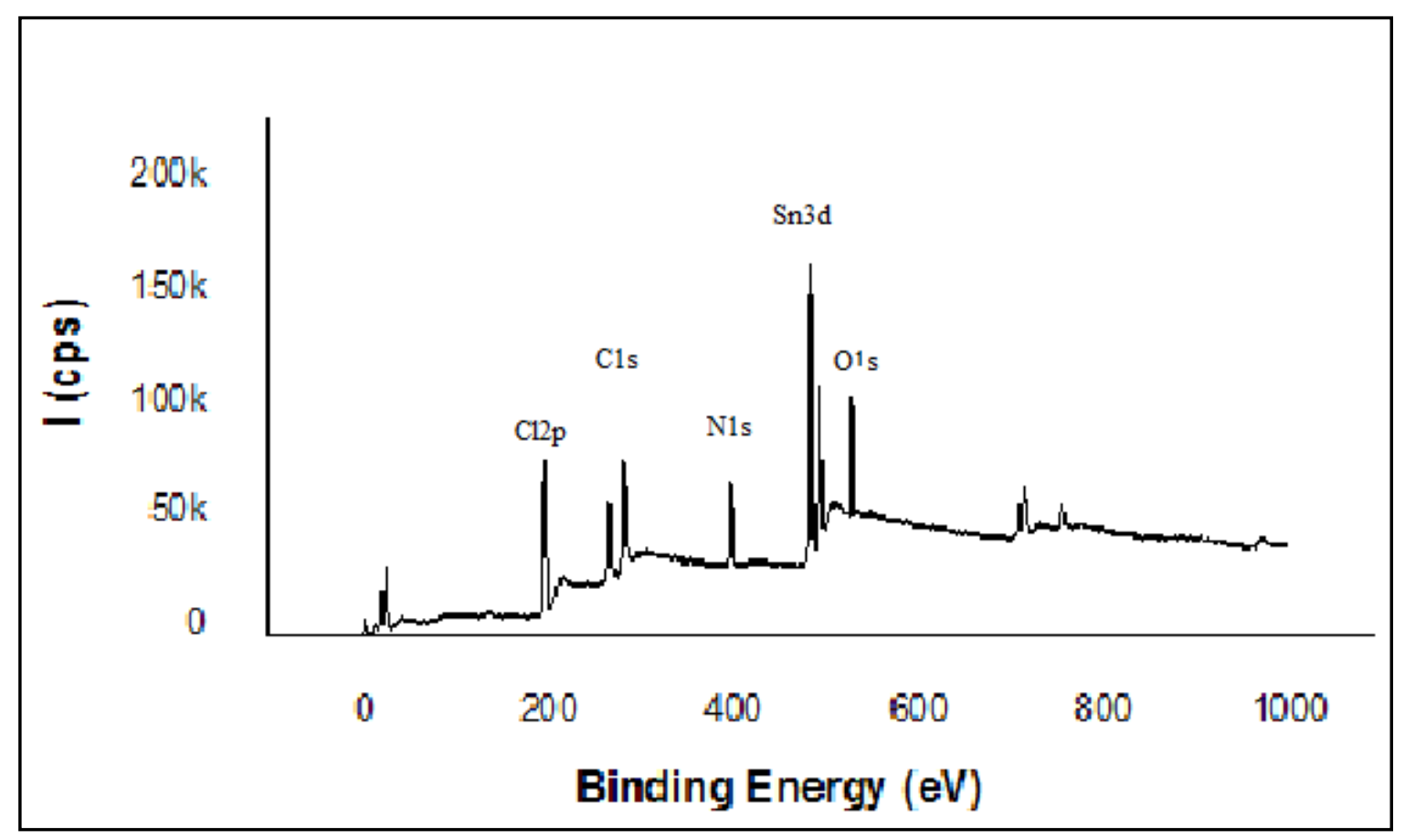

Fig. 13

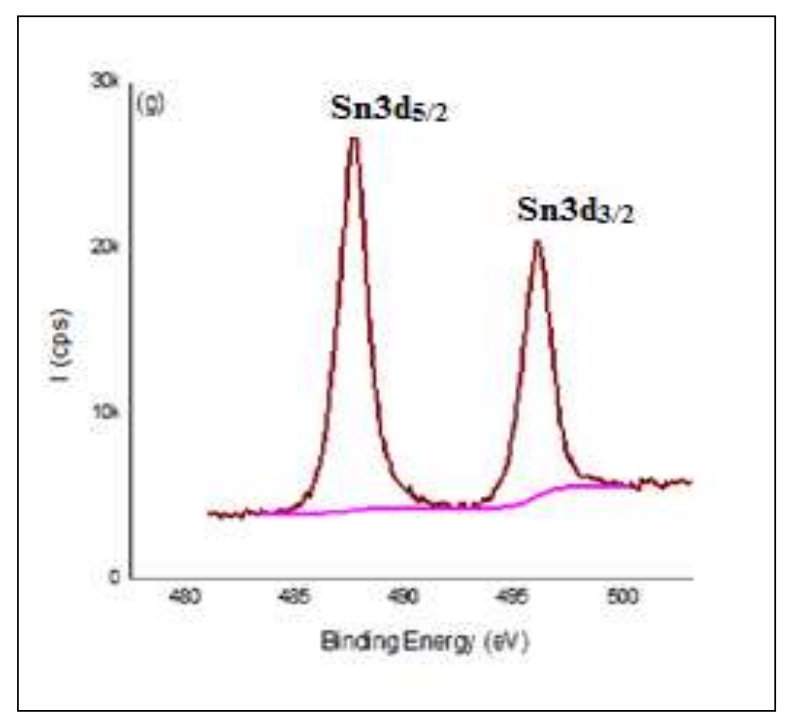

Fig. 14 
Table.1. Crystal data and structure refinement for $\left(\mathrm{C}_{5} \mathrm{H}_{14} \mathrm{~N}_{2}\right)_{2}\left[\mathrm{SnCl}_{6}\right]_{2} .5 \mathrm{H}_{2} \mathrm{O}$ crystal.

\begin{tabular}{|c|c|}
\hline Compound & $\left(\mathrm{C}_{5} \mathrm{H}_{14} \mathrm{~N}_{2}\right)_{2}\left[\mathrm{SnCl}_{6}\right]_{2.5} .5 \mathrm{H}_{2} \mathrm{O}$ \\
\hline Color/shape & Colorless/prismatic \\
\hline Space group & $P 22_{1} 2_{1} 2_{1}$ \\
\hline Temperature $\left({ }^{\circ} \mathrm{K}\right)$ & 293 \\
\hline Cell constants & \\
\hline a $(\AA)$ & $9.569(5)$ \\
\hline b $(\AA)$ & $11.747(5)$ \\
\hline$c(\AA)$ & $29.394(5)$ \\
\hline$\alpha(\mathrm{deg})$ & $90.000(5)$ \\
\hline$\beta(\operatorname{deg})$ & $90.000(5)$ \\
\hline$\gamma(\operatorname{deg})$ & $90.000(5)$ \\
\hline Cell volume $\left(\AA^{3}\right)$ & $3304(2)$ \\
\hline Formula units/unit cell & 4 \\
\hline$D_{\mathrm{x}}\left(\mathrm{Mg} \mathrm{m}^{-3}\right)$ & 1.924 \\
\hline Diffractometer/scan & $\begin{array}{c}\text { Buker APEX2 CCD area } \\
\text { detector }\end{array}$ \\
\hline $\begin{array}{l}\text { Radiation, graphite } \\
\text { monochromator }\end{array}$ & Mo-K $\alpha(\lambda=0.71073 \AA)$ \\
\hline Crystal dimensions (mm) & $0.44 \times 0.11 \times 0.09$ \\
\hline$\mu_{\text {calc }}\left(\mathrm{mm}^{-1}\right)$ & 2.51 \\
\hline Unique reflections & 9512 \\
\hline$\theta$ range $(\mathrm{deg})$ & $2.5 \leqslant \theta \leqslant 31.5$ \\
\hline Reflections with $\mathrm{I}>2 \sigma(\mathrm{I})$ & 7274 \\
\hline Range of $h, k, 1$ & $\pm 13,(-15,17),(-15,42)$ \\
\hline$F(000)$ & 354 \\
\hline Weight & $\begin{array}{c}1 /\left[\sigma^{2}\left(F_{\mathrm{o}}^{2}\right)+(0.037 P)^{2}+3.4139 P\right], \\
\text { where } P=\max \left[\left(F_{\mathrm{o}}{ }^{2}, \mathrm{o}\right)+2 F_{\mathrm{c}}{ }^{2}\right] / 3\end{array}$ \\
\hline$R=\sum|| F_{\mathrm{o}}-F_{\mathrm{c}} \| / \sum\left|F_{\mathrm{o}}\right|$ & 0.039 \\
\hline$R_{\mathrm{w}}$ & 0.105 \\
\hline Goodness-of-fit on $F^{2}$ & 1.06 \\
\hline Computer programs & SHELXL [18] \\
\hline
\end{tabular}


Table.3. Main interatomic distances $(\AA)$ and bond angles $\left(^{\circ}\right)$ involved in hydrogen bonds.

\begin{tabular}{|c|c|c|c|c|}
\hline D-H...A & $\mathrm{d}(\mathrm{D}-\mathrm{H})$ & $\mathrm{d}(\mathrm{H} \ldots \mathrm{A})$ & d (D...A) & $<\mathrm{DHA}$ \\
\hline $\mathrm{N} 1-\mathrm{H} 1 \ldots \mathrm{O} 4 \mathrm{~W}$ & 0.910 & 1.849 & 2.742 & 166 \\
\hline $\mathrm{N} 2-\mathrm{H} 2 \mathrm{~A} \ldots \mathrm{O} 2 \mathrm{~W}^{\mathrm{i}}$ & 0.900 & 1.987 & 2.873 & 167 \\
\hline N2-H2B...O1W ${ }^{\mathrm{ii}}$ & 0.900 & 1.993 & 2.857 & 160 \\
\hline N3-H3 ... O5W & 0.910 & 1.730 & 2.586 & 155 \\
\hline N4-H4D...O3W ${ }^{\mathrm{iii}}$ & 0.900 & 1.930 & 2.817 & 168 \\
\hline N4-H4C...O1 Wii & 0.900 & 2.001 & 2.854 & 157 \\
\hline $\mathrm{O} 1 \mathrm{~W}-\mathrm{H} 1 \mathrm{~W} \ldots \mathrm{Cl} 1^{\mathrm{iv}}$ & 0.851 & 2.630 & 3.362 & 144 \\
\hline $\mathrm{O} 1 \mathrm{~W}-\mathrm{H} 1 \mathrm{~W} 1 \ldots \mathrm{C} 12^{\mathrm{iv}}$ & 0.851 & 2.920 & 3.593 & 137 \\
\hline $\mathrm{O} 1 \mathrm{~W}-\mathrm{H} 2 \mathrm{~W} 1 \ldots \mathrm{O} 2 \mathrm{~W}$ & 0.852 & 2.047 & 2.865 & 160 \\
\hline $\mathrm{O} 2 \mathrm{~W}-\mathrm{H} 1 \mathrm{~W} 2 \ldots \mathrm{Cl} 2^{\mathrm{v}}$ & 0.851 & 2.469 & 3.283 & 160 \\
\hline $\mathrm{O} 2 \mathrm{~W}-\mathrm{H} 2 \mathrm{~W} 2 \ldots \mathrm{Cl} 7$ & 0.850 & 2.600 & 3.410 & 160 \\
\hline O3W-H1W3...Cl3 & 0.847 & 2.618 & 3.350 & 145 \\
\hline O3W-H1W3...Cl4 & 0.847 & 2.867 & 3.488 & 131 \\
\hline $\mathrm{O} 3 \mathrm{~W}-\mathrm{H} 2 \mathrm{~W} 3 \ldots \mathrm{Cl} 8^{\mathrm{vi}}$ & 0.850 & 2.585 & 3.432 & 174 \\
\hline O4W-H1W4 ...Cl4 & 0.977 & 2.870 & 3.633 & 135.7 \\
\hline $\mathrm{O} 4 \mathrm{~W}-\mathrm{H} 2 \mathrm{~W} 4 \ldots \mathrm{Cl} 12^{\mathrm{vii}}$ & 0.812 & 2.613 & 3.389 & 155 \\
\hline O5-H1W5 ...Cl8 & 0.859 & 2.791 & 3.573 & 152 \\
\hline $\mathrm{O} 5 \mathrm{~W}-\mathrm{H} 2 \mathrm{~W} 5 \ldots \mathrm{O} 3 \mathrm{~W}^{\mathrm{iv}}$ & 0.859 & 2.162 & 3.002 & 165 \\
\hline
\end{tabular}

Symmetry codes: (i) $\mathrm{x}-1, \mathrm{y}-1, \mathrm{z}$; (ii) $\mathrm{x}-1 / 2,-\mathrm{y}+1 / 2,-\mathrm{z}+1$; (iii) $-\mathrm{x}+2, \mathrm{y}+1 / 2,-\mathrm{z}+1 / 2$; (iv) $\mathrm{x}+1, \mathrm{y}$, $\mathrm{z}$; (v) $\mathrm{x}+1 / 2,-\mathrm{y}+3 / 2,-\mathrm{z}+1$; (vi) $-\mathrm{x}+1, \mathrm{y}-1 / 2,-\mathrm{z}+1 / 2$; (vii) $\mathrm{x}, \mathrm{y}-1, \mathrm{z}$. 